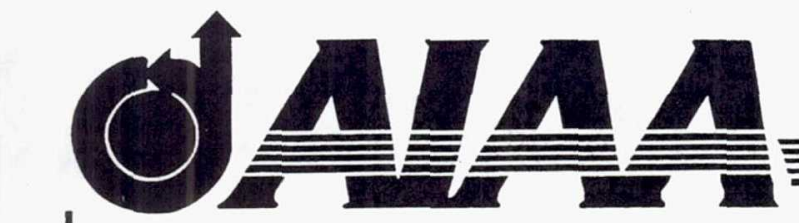

AIAA- 93-2919

Laser Velocimeter Measurements of the Flow Field Generated by a Forward-Swept

Propfan During Flutter

G.G. Podboy and M.J. Krupar

NASA Lewis Research Center

Cleveland, $\mathrm{OH}$

\author{
AIAA 24th \\ Fluid Dynamics Conference \\ July 6-9, 1993 / Orlando, FL
}

For permission to copy or republish, contact the American Institute of Aeronautics and Astronautics

370 L'Enfant Promenade, S.W., Washington, D.C. 20024 
NASA Technical Memorandum 106195

\section{Laser Velocimeter Measurements of the Flow Field Generated by a Forward-Swept Propfan During Flutter}

Gary G. Podboy and Martin J. Krupar

Lewis Research Center

Cleveland, Ohio

Prepared for the

24th AIAA Fluid Dynamics Conference

Orlando, Florida, July 6-9, 1993

\section{N/SA}




\title{
Laser Velocimeter Measurements of the Flow Field Generated by a Forward-Swept Propfan During Flutter
}

\author{
Gary G. Podboy and Martin J. Krupar \\ National Aeronautics and Space Administration \\ Lewis Research Center \\ Cleveland, Ohio 44135
}

\section{SUMMARY}

Results are presented from an investigation to measure the flow field generated by a forward-swept propfan operating in flutter at a low forward velocity. For comparison to the flutter condition, flow field data are also presented for a slightly reduced rotational speed just below flutter. The forward-swept propfan was tested as the front rotor of a counterrotating pusher propeller. A laser Doppler velocimeter (LDV) was used to measure the velocity field in planes normal to the model centerline downstream of the rotor and in planes of constant radius within the blade passages at each operating condition. A comparison of the data taken at the two different operating conditions indicated that the mean, time-averaged flow about the blades did not change drastically as the propfan rotational speed was increased from the stable operating point to the flutter condition. No regions of flow separation could be identified in the data plots of the mean intrablade flow field. The data also indicate that the relative flow about the blades remained subsonic during flutter operation. The blades were found to have a higher than expected tip loading at both operating conditions. This is thought to have been caused by the outer blade sections twisting under load to higher than expected effective blade angles. This high tip loading resulted in strong vortices and a very nonuniform flow downstream of the tips of the forward-swept blades. This high tip loading may also have caused the blade flutter.

\section{INTRODUCTION}

Since the mid 1970's, propfans have been investigated as a means of powering aircraft at high subsonic speeds. Advanced propeller models have been tested in wind tunnels to quantify the effects of varying such propeller design parameters as blade shape, number of blades, and inflow Mach number on the overall aerodynamic and acoustic properties of both single rotating and counterrotating configurations. The rotor blades used in these models are normally swept aft (opposite the flight direction), to take advantage of acoustic and aerodynamic benefits which result from the use of blade sweep at cruise operating conditions. To provide an acoustic benefit, the sweep is tailored to reduce noise through phase cancellation of thickness and loading noise harmonics. The aerodynamic benefit arises from decreased shock losses at the blade tips which operate transonically at cruise. Propfans have been shown to have a significant aerodynamic performance advantage relative to current turbofans at typical cruise conditions of Mach 0.8 and 35,000 feet altitude.

The counterrotating propellers that have been tested are inherently more fuel efficient than the single rotation propellers due to the ability of the downstream rotor to redirect the swirl generated by the front rotor back into the axial direction. Unfortunately, the counterrotating configurations are also inherently noisier than the single rotation propellers. Much of the increased noise for the counterrotating case occurs because the downstream rotor operates in the highly unsteady wake flow set up by the front 
rotor. Flow field non-uniformities in the front rotor wake flow can result due to viscous wakes, potential field nonuniformities created by the blades, leading edge and tip vortices, and flow separation from the blade surfaces. Interaction noise is produced when these mechanisms intersect the aft rotor blades. These nonuniformities, and the noise problems they create, are most severe at the takeoff condition when the propellers are operating at high power. Reducing the levels of these nonuniformities would tend to decrease the amount of interaction noise.

One possible means of obtaining a more uniform wake flow, especially in the region downstream of the blade tips, is to employ forward-swept rather than aft-swept blades in the front rotor of the counterrotating propfan. This concept was recently investigated by researchers at the United Technologies Research Center. Simonich et al. (ref 1) conducted a test in which a stationary vane having 45 degrees of sweep was positioned upstream of a rotating propfan. Separate tests were conducted with the vane swept forward and aft. Hot wire and flow visualization data were obtained to document the vane wake flow for the two different vane arrangements, while acoustic measurements were used to determine the effect of the wakes on interaction noise. For the case in which the vane was swept aft, a significant defect in the axial velocity field was measured within the tip vortex trailing downstream of the vane. This tip vortex was thought to be a combination of two vortices which formed separately along the tip and leading edge of the vane. For the forward-swept vane, the leading edge vortex moved inboard away from the tip, and consequently, two distinct vortices existed in the wake flow. The tip vortex in this case was found to have little axial velocity defect. The noise measurements revealed that the forward-swept vane generated significantly less interaction noise than the aft-swept vane at similar loading conditions. The large axial velocity defect measured downstream of the tip of the aft-swept vane was attributed to the outward migration of the leading edge vortex; this defect is thought to have been responsible for the increased interaction noise measured for the aft-swept case. Hence, this suggested a means of reducing interaction noise for advanced counterrotating propfans. By sweeping the front rotor blades forward, rather than aft, one could take advantage of the beneficial effects of sweep which result at cruise, while, at the same time, making the wake flow downstream of the blade tips more uniform. In addition, the forward-swept arrangement results in an increased spacing between the tips of the front and aft rotors. This allows the front rotor blade tip vortices more time to decay before reaching the aft rotor blades, and thus provides an additional acoustic benefit.

Lavrich et al. (ref 2) conducted a study in which a set of aft-swept propfan blades were operated in a forward-swept configuration by restaggering the blades approximately 180 degrees so that the leading and trailing edges were reversed. In this forward-swept arrangement the radial distribution of leading edge sweep peaked at a modest 20 degrees at $75 \%$ of the tip radius and decreased to about 10 degrees at the tip. Mini-tuft flow visualization and hot-wire and total pressure surveys were obtained to document the flow generated by the blades for both forward-swept and aft-swept arrangements. As was suggested by the swept vane study (ref 1), the forward-swept arrangement of the propfan provided a more uniform wake flow downstream of the blade tips than the aft-swept arrangement at similar loading conditions. However, the data obtained further inboard showed a massive separation of the flow from the suction surface of the forward-swept blades. This separation was attributed to the lack of formation of a leading edge vortex and resulted in a wide inboard wake of low momentum fluid downstream of each front rotor blade. Characteristics of the measured wakes were input into an acoustic prediction code which estimated that operating these blades in the forward-swept arrangement would result in more interaction noise being produced than if they were run as designed in an aft-swept arrangement. The authors concluded that in order to decrease the interaction noise generated by the forward-swept configuration it would be necessary to prevent the flow separation which occurred on the suction surface of the blades. They indicated that increasing the leading edge 
sweep would allow the formation of a leading edge vortex which could prevent the separation.

Recently a test was conducted in the NASA Lewis 9' X 15' Wind Tunnel of a forward-swept rotor which had 30 degrees of leading edge sweep over the outer $40 \%$ of the blade span. The initial purpose of this test was to determine if, at simulated takeoff conditions, these forward-swept blades would provide a more uniform wake flow than the aft-swept blades normally used in these counterrotating propfans. As part of this investigation, laser Doppler velocimetry (LDV) was used to measure the rotor wake characteristics of both this forward-swept rotor and a reference aft-swept rotor. The velocity field created by the aft-swept rotor was measured in several axial planes downstream of the rotor while operating at low and moderate power levels. A similar set of wake data was obtained downstream of the forward-swept blades only at low power since they fluttered at higher power conditions.

Due to the flutter, the emphasis of the laser velocimetry testing shifted from determining the rotor wake flow characteristics to measuring the flow field around the forward-swept blades during flutter. It was anticipated that the detailed flow field data obtainable with the laser velocimeter might identify an aerodynamic excitation mechanism which caused the flutter. One possibility was that the flutter was initiated by flow separation from the blades. This could be a blade pressure or suction surface separation, or in the form of a tip or leading edge vortex. Another possibility was that shock waves resulting from supersonic relative flow on the blades were causing the flutter. In an effort to identify an excitation mechanism, the LDV surveys conducted in support of the flutter investigation concentrated on measuring the near field flow within and just downstream of the blade passages. It was thought that the intrablade data would be especially valuable in determining the cause of the flutter. This data could be used to identify if flow separation had occurred and/or the likelihood of having any regions of supersonic relative flow in the vicinity of the blades.

This data was also obtained for the purpose of generating a data base that could be used to verify the output of computational codes which have been developed to predict flutter. For reliable flutter predictions, it is necessary to accurately represent both the flow about the blades and the structural characteristics of the blading. Unfortunately, if there is some discrepancy between code predictions and experiment, there is normally little information available to determine if the fault lies with the theoretical models of the flow field or the models of the blade structure. The detailed velocity data obtained during this test can be used to quantify the ability of a code to simulate the mean, time-averaged flow about the blades during flutter.

The purpose of this paper is to present LDV measured velocity data obtained during this flutter testing. This is believed to be the first laser velocimeter data obtained on the flow field produced by an unducted rotor during flutter. Data is presented for two model operating conditions at a freestream velocity of Mach 0.2 - an rpm condition at flutter, and a condition at which the rpm was reduced just enough to get out of flutter. Data was obtained at the same locations relative to the model at each of the conditions, thus permitting the two flow fields to be compared. Data is presented which depicts the flow field occurring just downstream of the forward-swept front rotor blades at each of the two operating conditions. Data depicting the flow within the blade passages at the two conditions is also presented and compared. A discussion of the apparent cause of the flutter and of the significance of various wake flow non-uniformities in the production of interaction noise is also provided. 


\section{SYMBOLS}

D propeller diameter, $\mathrm{ft}$

$\mathrm{J} \quad$ advance ratio; $\mathrm{U}_{\mathrm{o}} /(\mathrm{nD})$

n rotational speed, rev/sec

r elemental blade radius, in.

$\mathrm{U} \quad$ axial velocity, $\mathrm{ft} / \mathrm{sec}$

V tangential velocity, $\mathrm{ft} / \mathrm{sec}$

$\mathrm{U}_{\mathrm{O}} \quad$ free-stream (axial) inflow velocity, $\mathrm{ft} / \mathrm{sec}$

$\alpha \quad$ absolute flow angle, $\operatorname{deg}\left(\alpha=\tan ^{-1}(\mathrm{~V} / \mathrm{U})\right)$

$\beta_{3 / 4}$ blade stagger angle at $75 \%$ of tip radius, deg (measured from the plane of rotation)

\section{Subscripts:}

0 free-stream condition

ens ensemble averaged

pl phase-locked averaged

\section{EXPERIMENTAL APPARATUS AND PROCEDURE}

\section{Test Model}

Figure 1 shows the counterrotating propfan model installed in the 9' $\mathrm{X} 15^{\prime}$ Wind Tunnel. As can be seen from the figure, this is a pusher propeller configuration with twelve forward-swept front rotor blades and ten aft-swept back rotor blades. The blades were designated F39S and A31 for the front and aft rows, respectively. All of the blades were made of graphite plies laid up over a titanium spar. The planform shapes of the F39S and A31 blades are illustrated in figure 2. The leading edges of these blades sweep forward at an angle of approximately 30 degrees over the outer $40 \%$ of the blade span. The blade angles at 75 percent of the propeller tip radii $\left(\beta_{3 / 4}\right)$ were set at 35.0 degrees on the front rotor and 38.2 degrees on the aft rotor. The front rotor diameter was 26.0 inches, while the aft rotor diameter was 24.8 inches. The axial spacing between the pitch change axes of the two rotors was 7.22 inches, a distance equivalent to $27.6 \%$ of the front rotor diameter. Both the flutter and the below flutter data were acquired at a tunnel freestream flow of Mach 0.2 . The front rotor rotational speed was set at 5900 RPM during acquisition of the flutter data, and at 5600 RPM for the below flutter condition. The 
corresponding front rotor advance ratios $(\mathrm{J})$ were 1.07 and 1.127 at 5900 and $5600 \mathrm{RPM}$, respectively.

\section{$\underline{\text { Laser Velocimeter System and Data Acquisition }}$}

The laser Doppler velocimeter (LDV) used was a four-beam, two-color, backscatter system which permitted the measurement of two components of velocity simultaneously. Two green beams were used to measure the axial components of velocity, while two blue beams allowed the measurement of radial and tangential components. Axial and radial velocities were measured above the model in a vertical plane passing through the model centerline. Axial and tangential components were measured in a horizontal plane on the side of the model (fig 3). The LDV probe volume, which was ellipsoidal in shape, had a diameter of approximately $0.11 \mathrm{~mm}(0.0043 \mathrm{in})$ and was roughly $6.0 \mathrm{~mm}(0.24 \mathrm{in}$.) long.

The tunnel flow was seeded with polystyrene latex (PSL) spheres manufactured at the NASA Lewis Research Center to be less than or equal to one micron in diameter. Due to the manufacturing process, these solid particles are supplied suspended in water. Before introduction into the tunnel this solution is diluted by mixing it with 200 proof ethyl alcohol. This solution was then sprayed into the tunnel at a location 80 feet upstream of the test section. The liquid evaporates in the time it takes to reach the model, leaving behind the solid PSL seed on which the LDV data was obtained.

Figure 4 illustrates the axial and radial locations relative to the model at which data were obtained during LDV runs conducted to support the flutter investigation. Figure $4 \mathrm{a}$ shows measurement locations for the flutter operating condition, while figure $4 \mathrm{~b}$ gives locations for the below flutter condition. Data were acquired by making either radial traverses of the measurement volume at a constant axial location or axial traverses at a constant radial location. All three velocity components were measured in the constant axial planes labeled in the figure as stations $1 \mathrm{~A}$ and $2 \mathrm{~A}$. Station $1 \mathrm{~A}$ and $2 \mathrm{~A}$ are 0.53 and 1.79 inches, respectively, downstream of the pitch change axis of the front rotor blades. For most of the measurement locations within these two planes, the axial velocities were measured twice - once in the vertical plane above the model and once in the horizontal plane on the side. For the constant radial intrablade surveys only axial and tangential components were measured. In order to measure radial velocities with this LDV system, it was necessary to position the measurement volume in the vertical measurement plane above the model. When positioned to obtain data inside the blade passages in this plane, the blades blocked access to the required measurement locations, making it impossible to measure the radial velocities.

Shaft angle encoders, coupled with once-per-revolution signals from the rotors, were used to determine the angular position of each rotor whenever a velocity measurement was made. Two encoders were used for each of the two velocity components being measured. One of these two encoders was fed with the once-per-rev signal from the front rotor, while the other encoder received the signal from the aft rotor. These encoders segmented the 360 degrees of rotor revolution occurring between two consecutive once-per-revolution pulses into 720 bins. Each time a velocity measurement was made, each of the two encoders corresponding to that velocity component was sampled to determine the number of bins generated since the occurrence of the previous once-per-rev pulse. These bin numbers reference the velocity measurement relative to the circumferential location of the blades of each rotor.

Data were acquired at each location over many rotor revolutions until a sufficient amount of data had been obtained to accurately resolve the flows occurring within the individual blade passages. The data were acquired in "random" mode, meaning that the two LDV channels obtained data independently. 
Data acquisition was stopped on both channels when one of the two channels had obtained a preset number of measurements. During the runs, settings within the two LDV signal processors were adjusted so that roughly the same number of measurements were acquired on each of the two velocity components. Normally when the probe volume was positioned at a radial location near the tip vortex, the system was programmed to accept data until 32000 velocities were measured on at least one of the two channels. This results in an average of about 44 measurements per bin for each of the 720 bins. For locations away from the tip vortex, data acquisition was halted at 16000 measurements, or an average of 22 measurements per bin. On-line plots indicated that these were a sufficient number of measurements to resolve in detail the flow across the complete rotor.

\section{$\underline{\text { Data Reduction }}$}

Data reduction consists of performing a series of successive averaging operations to compress to a presentable format the nearly 13 million velocity measurements obtained during this flutter investigation. Figure 5 provides an illustration of the data compression process. Figure 5a shows an example of a circumferential distribution of 32000 velocity measurements across the 720 bins of a complete rotor revolution. The plot shows radial velocities measured during flutter at a radius of 12.75 inches, just downstream of the front rotor at axial station 1A (see figure 4). These velocities are shown sorted relative to the circumferential position of the front rotor and clearly indicate the influence of the front rotor blades. Any influence of the aft rotor blades would be smeared circumferentially in this view. In a similar manner these velocities could be plotted relative to the aft rotor position, but since this data was acquired far upstream of this rotor, such a plot would not show any recognizable blade-to-blade variation in the flow. All the data presented herein will be plotted relative to the position of the front rotor only. The first step in the data compression process is to compute the ensemble-averaged mean velocity occurring within each of the 720 bins (figure $5 \mathrm{~b}$ ). The plot shows that at this location in the flow field, the mean radial velocity distributions downstream of the twelve different blade passages are very similar from blade-to-blade. Mean velocity distributions of the velocity components obtained at the other measurement locations also show a high degree of passage-to-passage similarity (for further discussion of this see the Results section). Consequently, little information is lost in averaging the data of the twelve blade passages into one "composite" passage. The result of this phase-locked averaging process is illustrated in figure $5 \mathrm{c}$; this plot reveals that this averaging process retains the essential character of the flow of the individual passages. A final step in the data reduction process was to compute a circumferentially averaged velocity for each component by computing the mean of the phase-locked averaged velocities. For the data presented in this example, the circumferentially averaged value was found to be $-60.3 \mathrm{ft} / \mathrm{sec}$. A positive radial velocity indicates flow away from the centerbody, and a positive tangential velocity indicates a flow in the direction of rotation of the front rotor (counter-clockwise looking upstream). This sign convention is illustrated in fig. 3 .

\section{RESULTS AND DISCUSSION}

\section{Axial Plane Surveys: Time-Averaged Flow}

Figure 6 shows the phase-locked averaged velocities measured during flutter in the axial plane perpendicular to the model centerline at axial station 1A. The view in this figure is from behind the measurement plane looking upstream. Outlines of the front rotor blades are shown superimposed on the plot to illustrate the approximate location of the blades. In this plot the flow field of the "composite" blade passage (from the phase-locked averaging) has been duplicated to span more than one passage 
to provide a better view of any transitions which may occur across the boundaries of the passage. One quadrant of a complete rotor flow field is illustrated. The axial velocities are represented in the figure by the color contours; the plotted vectors depict the secondary velocities determined by vectorially adding the phase-locked averaged radial and tangential velocities measured at equivalent locations relative to the propeller blades. Secondary velocities are not plotted for radial locations less than 11.25 inches since radial components could not be measured within the blade passages.

Several flow field features can be identified in figure 6. Vortices trailing from the tips of these blades are evident from the clockwise swirl of the secondary velocity vectors downstream of the blade tips and by the rapid change in axial velocity which occurs as one proceeds radially through these regions. The velocity perturbations occurring due to these vortices are significantly higher than those which occur anywhere else in the flow field. Phase-locked averaged axial velocities ranging from 40 to $560 \mathrm{ft} / \mathrm{sec}$ and phase-locked averaged radial velocities ranging from +110 to $-270 \mathrm{ft} / \mathrm{sec}$ were measured within these vortices. These data indicate that a very nonuniform wake flow was generated by the tips of these forward-swept blades. The viscous blade wakes shed from the outer portions of the blades show up in the color contours as dark green radial lines spanning in radius from $r=11.0$ to $r=12.0$ inches. The secondary velocity vectors (computed from the vector sums of the radial and tangential components) reveal increased tangential velocities within the blade wakes, indicating a strong tendency for this viscous flow to be dragged along in the direction of rotation of the blades. The narrow width of the wake suggests that upstream of the blade trailing edge the flow was attached to the blade surface. The axial velocity contours plotted for the intrablade radial locations $(r<11.0$ in) also depict a normal, attached mean flow. These contours do not rule out the possibility that the flow did separate from the blades; it is possible that the flow separated upstream of this axial location and then re-attached. They do suggest, however, that if separation occurred, it was not massive, and that the flutter was not caused by massive blade stall.

Figure 7 shows the phase-locked averaged velocities measured during flutter $(5900 \mathrm{rpm})$ at axial station 2A (just downstream of the front rotor trailing edge). In this plane axial velocities were measured further inboard than at station $1 \mathrm{~A}$, with the innermost radial location within 0.2 inches of the hub surface. A complete set of secondary velocities could not be measured at the innermost radial locations since at some angular orientations of the front rotor the blades blocked the view of the optics used in the measurement of these components. The axial velocity contours show the boundary layer which forms along the centerbody and the deficits occurring within the viscous blade wakes over the entire blade span. The viscous blade wakes are shown to be relatively wide over the outer portions of the blade span, between the radial locations of 8.5 and 11.5 inches. Wider wakes are expected at these outer radial locations due to the spreading which occurs as the wakes convect downstream. Because of the forward sweep of the front rotor blades, the outer measurement locations are further downstream of the blade trailing edges. Consequently, the wakes measured further outboard have had more time to spread circumferentially. It is worth noting the lack of any significant perturbation in the axial velocity contours due to a hub vortex. This indicates that if a hub vortex did form it is much weaker than the tip vortex and, therefore can be expected to contribute much less to the generation of interaction noise.

It was suspected that the manner in which the data was reduced might also be responsible for some of the increase in the wake width shown at the outer radial locations. Due to the time-averaging effect of the data reduction process, thin, oscillating wakes would be smeared circumferentially and appear wider in these plots. However, similar increases in the wake width were found for each of the other operating conditions at which LDV data were obtained downstream of the forward-swept rotor. This includes two nonflutter conditions other than the below flutter condition discussed in this report. At these 
conditions the blade wakes would not be expected to oscillate appreciably. Therefore it does not appear that the increased wake width noted at the outer radial locations was caused by a smearing of the wakes due to the data reduction process.

Figure 8 shows the phase-locked averaged velocities measured at axial station $2 \mathrm{~A}$ for the below flutter (5600 $\mathrm{rpm}$ ) operating condition. The induced axial and secondary velocities shown here are reduced in magnitude relative to those provided in figure 7 for the higher speed $(5900 \mathrm{rpm})$ condition. This includes the region of high induced axial velocity inboard of the center of the tip vortex, which is shown to cover a smaller area at this lower speed condition. Hence, these LDV data show, as expected, that the induced velocities decrease with decreasing rotational speed. Except for these speed-related differences, the velocity fields of the two operating conditions are very similar. The data indicate that the mean flow field did not change drastically as rotational speed was increased from the below flutter to the flutter condition. This includes the flow within the viscous blade wakes. The thickening of the wake at the outer radii noted above in the discussion of the flutter data, is also shown to occur at this below flutter condition. It was originally thought that a comparison of the flutter and below flutter data obtained at this axial station might suggest that flow separation was the cause of the flutter. These plots indicate that the flow was not massively separated at either operating condition.

The axial velocities measured at axial station $2 \mathrm{~A}$ are presented again as color contours in figure 9. Unlike the preceding plots in which the data were averaged into a composite passage, in this figure the ensemble averaged axial velocities measured across the complete rotor are plotted. The data measured during flutter is presented at the left of the figure, while the below flutter data is plotted at the right. The flows of the individual passages show up clearly in these plots with a high degree of passage-to-passage mean flow similarity indicated at each of the conditions. This is illustrated again in figure 10 where the data have been replotted after subtracting, for each condition, the corresponding phase-locked axial velocity distributions of the "composite" passage from each of the twelve individual passage flows. Hence, the color contours plotted here correspond to levels of axial velocity deviation from the average passage flow. Except for some small regions near the centers of the tip vortices, the deviations are shown everywhere to be less than $40 \mathrm{ft} / \mathrm{sec}$. The nonviscous portions of the flow show even better similarity, with deviations of less than $20 \mathrm{ft} / \mathrm{sec}$. Note that the deviations downstream of the individual blades tend to be similar for the two conditions. For example, the wakes of the blades labeled 1, 4, 8 and 10 tend to show deviations above the average at each condition, while blades 2 and 11 show deviations below the average. This suggests that those deviations which are shown for the flutter condition are not a result of the flutter, but instead were due to some other cause such as slight mismatches of blade angle. The high degree of passage-to-passage similarity shown for the flutter condition also suggests that over the length of time required to obtain the data at each measurement location (typically $90 \mathrm{secs}$ ), all the blades were dynamically similar; that is, the flutter does not appear to have been isolated to only some of the blades.

The wake flow data presented above can be used to determine if vortices form along the leading edges of these forward-swept blades and convect downstream at these operating conditions. Leading edge vortices normally start to form at an upstream location on a blade and roll up in the direction of the leading edge. For an aft-swept blade the leading edge vortex begins to form inboard, follows the leading edge outward, and is convected downstream at a location near the blade tip. In this case, the leading edge and tip vortices are thought to merge into a single vortex. For a forward-swept blade it is expected that the leading edge vortex begins forming near the tip, follows the path of the leading edge radially inward, and is convected downstream at a radial location inboard of the tip vortex. Therefore, the tip and leading edge vortices would exist independently downstream of the rotor. The data shown 
in these figures, however, do not give any indication that leading edge vortices exist in these flow fields. This probably means that the leading edge of these blades was not swept forward enough to allow the formation of a leading edge vortex at these low power operating conditions.

The absence of leading edge vortices in the wake flow set up by the forward-swept blades is also indicated by figure 11. Contours of axial vorticity computed from the axial station $2 \mathrm{~A}$ data are shown for each of the two operating conditions. Also depicted on each plot are the secondary velocities from which the axial vorticity levels were calculated. These contours indicate that the tip vortex is the dominant vortical structure in the wake flow. Vortex sheets are shown to be shed from the trailing edges of the blades, but the peak vorticity levels within the sheets are much lower than those found within the the tip vortices. The relatively high tip vortex strength indicates that the tip regions of these forward-swept blades were highly loaded. Considering how well the tip vortices stand out in these contour plots, it is thought that if leading edge vortices were forming on these blades, that they too would show up in these contours. Since they are not shown, it is evident that no separate leading edge vortices exist in the front rotor wake flow at either operating condition.

As discussed in the introduction section, it was expected that, for a given loading condition, the tips of these forward-swept blades would provide a more uniform tip wake flow than aft-swept blades, and that this would result in decreased interaction noise. The more uniform tip wake flow was expected for a forward-swept blade since, if a leading edge vortex were to form, it would not migrate outboard and merge with the tip vortex. This concept was demonstrated in earlier studies using both a forward-swept stationary vane (ref 1 ) and a forward-swept rotor (ref 2). In contrast to the data obtained during these previous tests, the F39S blades tested here generated strong tip vortices which produced a very nonuniform wake flow downstream of the blade tips. As shown in a previous paper (ref 3 ), the axial velocity field generated by these forward-swept blades was more nonuniform than that produced by a conventional aft-swept rotor at the same power loading condition. This forward-swept configuration was also found to generate more interaction noise than a propfan which had aft-swept blades in each rotor. Sideline acoustic data indicated that the interaction tone levels of the forward-swept configuration were up to $8 \mathrm{db}$ higher than those of the conventional aft-swept configuration.

As discussed in Ref 3., the higher interaction noise produced by the forward-swept configuration has been linked to a higher than expected twisting of the blade tips which is thought to have occurred as the model and wind tunnel were brought up to operating speed. Figure 12 shows radial distributions of circumferentially-averaged axial and tangential velocities measured at axial station $2 \mathrm{~A}$ for both the flutter and below flutter operating conditions. Also shown on the figure are velocity profiles measured in the wake of a reference aft-swept front rotor operating at $6500 \mathrm{RPM}$ with the blade angle, $\beta_{3 / 4}$, set at 38 degrees. The data measured downstream of this aft-swept front rotor were obtained in a plane 0.63 inches downstream of axial station $2 \mathrm{~A}$ ( $0.63 \mathrm{in}$. represents $8.7 \%$ of the $7.22 \mathrm{in}$. rotor-to-rotor spacing). The figure shows that there are significant differences between the wake flows developed by the two different sets of front rotor blades. The data measured downstream of the aft-swept rotor shows both the axial and tangential components increasing gradually with decreasing radius from the tip until each distribution peaks inboard of 50\% span. These data indicate that the aft-swept blade loading peaked at an inboard location and the blade tips were relatively lightly loaded. This is the sort of radial loading distribution that one would expect for a properly designed rotor of a counterrotating configuration. In contrast, the velocity distributions measured downstream of the forward-swept blades show high circumferentially-averaged axial and tangential velocities downstream of the blade 
tips, indicating a higher than normal tip loading. This high tip loading is shown to occur at both the flutter and below flutter operating conditions. It is thought that this was caused by the tip regions of the blades twisting under load to higher than expected effective blade angles. This high tip loading is responsible for producing strong tip vortices which, in turn, produce high noise levels when they interact with the downstream rotor blades.

Interaction noise is generated when the downstream rotor blades experience unsteady lift fluctuations created by the nonuniform wake flow of the front rotor. These nonuniformities act to change the effective angles-of-attack of the blade sections comprising the downstream rotor. The contours plotted in figure 13 were generated in an attempt to illustrate to what extent these effective angles-of-attack could be expected to vary as the downstream blades rotate through the wake flow. These contours represent the absolute flow angles computed from the measured phase-locked averaged axial and tangential components measured at axial station $2 \mathrm{~A}$ for each of the two operating conditions. Also plotted are vectors which represent the secondary velocities measured at station $2 \mathrm{~A}$. The absolute flow angle, alpha, is defined as

$$
\alpha=\tan ^{-1}(\mathrm{~V} / \mathrm{U})
$$

where $\mathrm{V}$ and $\mathrm{U}$ are the local tangential and axial velocities, respectively. In general, at a given radius, the greater the variation in flow angle, the higher the level of unsteady lift one can expect on the downstream rotor airfoil sections. The figure shows dramatic changes in flow angle due to both the viscous blade wakes and the tip vortices. During flutter, at a radial location near the center of the tip vortex, the mean absolute flow angle varies from near +2 degrees away from the vortex to -30 degrees near the center of the vortex. At inboard radial locations, where the viscous blade wakes are primarily responsible for the nonuniformity of the flow, typical flow angle changes of 28 degrees (from +10 to +38 degrees) are indicated. These results confirm that both the tip vortices and the blade wakes can be expected to contribute significantly to the generation of interaction noise.

Besides generating high levels of interaction noise, the high tip loading may also be responsible for the blade flutter. This statement is made, in part, because other likely causes of the flutter can be ruled out. It has already been shown that massive flow separation did not cause the flutter. Later it will be shown that it is unlikely that the flow about the blades ever became supersonic. Therefore, it does not appear that shock waves could have caused the flutter. However, the loading distributions for the forward-swept blades indicated in figure 12 are much different than that of a typical counterrotating blade design. The high tip loading indicated by these distributions could have caused the flutter.

\section{Constant Axial Plane Surveys: Unsteady Flow}

Most of the data presented above has focused on depicting the mean, time-averaged flow field set up by the front rotor. An attempt to illustrate the wake flow unsteadiness measured at axial station $2 \mathrm{~A}$ for each operating condition is provided by the color contours plotted in figure 14. To aid in relating locations within these contours to previously identified flow features, the phase-locked averaged secondary velocity vectors presented earlier for this axial station are overlayed on these plots. The plotted unsteadiness contours for each condition were computed by first folding the individual axial velocities measured downstream of the twelve blade passages into one passage. (This is different than the normal data reduction process. In the data reduction process, the data were ensemble averaged, then folded into one passage i.e. phase-locked averaged. Here the raw, unaveraged data is folded into 
one passage.) The standard deviation of the axial velocities falling within each bin at each radial location was then computed and normalized by the freestream velocity of $220 \mathrm{ft} / \mathrm{sec}$. Finally, the resulting values were made to represent a percentage of the freestream velocity by multiplying by 100 . Provided no sources other than turbulence contribute to the measured unsteadiness, the above mentioned standard deviations represent the local axial turbulent velocities. Outside the rotor wake in the freestream, the normalized axial turbulent velocity is equivalent to the axial turbulence intensity. For a number of reasons, however, the computed standard deviations are expected to be biased high relative to the actual local turbulent velocities. These reasons include, flow field unsteadiness created by the blade flutter, passage-to-passage variations in the flow, mean velocity gradients along the length of the LDV probe volume, potential field non-uniformities created by the aft rotor blades, and low frequency oscillations of the tunnel flow. Because of these sources it is thought that the plotted data do not accurately represent the flow turbulence; they do, however, provide some insight as to how the unsteadiness of the flow varies both locally about the blades and as the operating condition changes from below flutter to flutter. As can be seen from the plots for each condition, the unsteadiness is highest within those regions having the steepest velocity gradients - the tip vortices, the blade wakes and the hub boundary layer. A slight increase in the unsteadiness is shown to occur near the hub just to the right of the viscous blade wake. This may be due to the presence of a hub vortex. The shapes of the unsteadiness contours are similar for the two operating conditions, but as would be expected, during flutter the near-blade region of high unsteadiness is larger and the peak levels are greater. The maximum unsteadiness level measured within the blade wake at flutter approached $28 \%$ of the freestream velocity, or $64 \mathrm{ft} / \mathrm{sec}$. At this point in the flow the mean axial velocity was measured to be about $280 \mathrm{ft} / \mathrm{sec}$. If the data measured at this location followed a gaussian distribution, $95 \%$ of the axial velocity measurements would fall within a range about the mean of roughly $+/-128 \mathrm{ft} / \mathrm{sec}(+/-2$ standard deviations). This indicates, as do the other plotted contours, a highly unsteady rotor wake flow - especially in the viscous regions. This should be kept in mind when viewing the phase-locked averaged contour and vector plots, which tend to show nice, smooth variations of the mean flow. These unsteadiness contours indicate that rather severe changes in the flow field can occur over time even when locked in a given position in the rotating reference frame of the front rotor. Nonuniformities significantly greater than those suggested above by the mean, time-averaged views of the wake flow were measured.

\section{Constant Radial Plane Surveys}

Figure 15 presents phase-locked averaged axial velocities measured within the blade passages of the front rotor during flutter. Shown are the results of surveys made at six different radial locations between $\mathrm{r}=10.0$ and $\mathrm{r}=13.0 \mathrm{in}$. The view depicted is from outside the front rotor blade row looking radially inward. In this view the tunnel flow would be moving from right to left. Constant-radius blade airfoil sections are shown superimposed on the contours. The location and orientation of these sections were subjectively chosen based on where the airfoils seemed to "fit" in the data. The rotation of the blades would move these airfoil sections upward in this view, making the upper side of the blade the pressure surface and the lower side the suction surface. The survey for $r=13.0$ in., at the left of the figure, shows data measured very close to the blade tip. In fact, the outermost airfoil section is angled slightly such that the leading edge was just outboard, and the trailing edge just inboard, of this radius. This outermost survey shows a band of high speed flow with axial velocities approaching $560 \mathrm{ft} / \mathrm{sec}$ on the suction side of the blade back to about $80 \%$ chord. This is abruptly followed by a region of retarded flow in which the mean axial velocities drop to levels as low as $40 \mathrm{ft} / \mathrm{sec}$. This transition from high to low axial velocity results from the inward movement of the tip vortex. Upstream of the transition point the center of the vortex is outboard of this radius, and the measurements were obtained in the high axial 
velocity region below the center of the vortex. The axis of the vortex passes into the page at about $80 \%$ chord, so downstream of this point the data were obtained in the low axial velocity region outboard of the vortex center. At $r=12.5$ in., the band of high axial velocity shown on the suction side of the blade and downstream of the blade indicates that at this radius the LDV probe volume was on the underside of the tip vortex. Hence, these contours indicate that in the region between the trailing edge of the blade and axial station $2 \mathrm{~A}$, the vortex axis lies between $\mathrm{r}=12.5$ and $\mathrm{r}=13.0 \mathrm{in}$. This is in agreement with the constant axial station 1A and 2A data shown previously in figures 6 and 7 . The contours also show very high loadings on the blade tip region due to the presence of the tip vortex. Further inboard, at $r=12.0$ in., the tip vortex still has some influence on the flow, but it is not as significant as at the outer two radii. The viscous blade wake, which can not be identified in the data of the two outermost radial cuts, shows up in the contours of the data obtained at the four inner radial locations. These data indicate that the blade wakes become more pronounced as one proceeds inward from the tip. This would be expected since both blade chord and thickness increase with decreased radius over this span of the blade. These data also suggest that the wake width increases slightly with distance downstream of the trailing edge. Note also that none of these radial cuts indicate any form of flow separation due to blade stall. This gives further confirmation that the flutter was not caused by massive blade stall.

The intra-blade, phase-locked averaged axial velocities measured while the model was operating at the below flutter condition are presented in figure 16. Each of the four radial cuts presented here show a high degree of similarity to the data obtained at the same radial locations during flutter operation. Like the comparison made between the flutter and below flutter data measured in the constant axial plane at station 2A, the only differences which can be noted in the two sets of intrablade data are those which can be attributed to the difference in rotor speed between the two operating conditions. As expected, the flow accelerates to lower peak velocities on the suction side of the blade at the below flutter condition. The data also suggests that the tip vortex is weaker and has less of an affect on the intra-blade flow at the lower speed operating condition. This is to be expected since at the higher rpm flutter condition, the blade sections operate at higher incidence angles, which lead to higher blade loadings and stronger tip vortices.

Relative Mach number contours computed from the phased-locked averaged axial and tangential velocities measured within the blade passages at the flutter condition are presented in figure 17. Since radial velocity components could not be measured inside the blade passage, they could not be included in the calculation of relative Mach number. These contours were computed in an effort to determine whether or not it was likely that the relative flow about the blades ever became supersonic. If so, it would be possible that the flutter was caused by shock waves resulting from the supersonic flow. The plotted contours range in value from 0.32 in the viscous blade wake at $r=10.0$ to 0.81 on the suction side of the blade at $r=12.5 \mathrm{in}$. Hence they indicate that the mean relative flow within the front rotor blade passages was subsonic, and that the flutter was not shock induced. It is thought that the same conclusion would be reached even if the radial components of velocity could have been included in the relative Mach number calculation. At the point in the flow where the relative Mach number reached a maximum of 0.81 , a phase-locked averaged radial velocity having a magnitude of $670 \mathrm{ft} / \mathrm{sec}$ would be required for the flow to reach the sonic speed. This is larger than any radial velocity measured at any point in the wake flow. It is very unlikely that radial velocities of this magnitude existed within the blade passage. Consequently, it is also unlikely that the mean flow ever became supersonic.

These time-averaged views of the flow field, however, do not confirm that supersonic flow never existed on the blades at the flutter operating condition. It could be that the unsteady oscillations of the flow about the mean were such that supersonic relative flow could exist for brief periods of time within 
the blade passages. It might be possible to determine whether or not this could happen by examining the unsteady variation of the flow about the mean. Figure 18 shows unaveraged data obtained at the location in the flow where the contours of figure 17 indicated that the relative Mach number reached the maximum value of 0.81 . Unaveraged axial velocities are plotted vs. the front rotor position in figure $18 \mathrm{a}$, while unaveraged tangential velocities are plotted in figure $18 \mathrm{~b}$. This data was obtained during flutter just upstream of the leading edge of the blade at $r=12.5 \mathrm{in}$. The contours of figure 17 indicate that the relative Mach number peaked at this radius at a point where the flow accelerated around the leading edge to the suction side of the blade. The velocities resulting from this acceleration are shown in the unaveraged velocity distributions as the positive and negative peaks in the axial and tangential distributions, respectively. It can be seen from figure 18 that unaveraged axial velocities as high as 500 $\mathrm{ft} / \mathrm{sec}$ and unaveraged tangential velocities as low as $-300 \mathrm{ft} / \mathrm{sec}$ were measured in this acceleration region. The combination of these two extreme velocities yields a relative Mach number of 0.90 .

Assuming both of these components could exist simultaneously, in order for the flow to reach the sonic speed the radial velocity component would be required to have a magnitude of $367 \mathrm{ft} / \mathrm{sec}$. It is unlikely that radial velocities of this magnitude exist at this location in the flow field. Examination of other unaveraged data plots indicate that it is unlikely that the flow within the vicinity of the blades ever became supersonic. Hence it does not appear that shock waves could be responsible for causing the blade flutter.

\section{Conclusions}

Data have been presented which illustrate the flow about the forward-swept front rotor blades of a counterrotating propfan operating in a Mach 0.2 freestream at two operating conditions - a condition at flutter, and a condition at which the rpm was reduced just enough to get out of flutter. Based on these data the following observations can be made:

1) Tip vortices were the dominant vortical structures in the wake flow. Leading edge vortices did not form on these forward-swept blades at either operating condition. There is some evidence that hub vortices were generated, but they are much weaker than the tip vortices.

2) Circumferential variations in flow angle measured across the tip vortices were found to be of about the same magnitude as the flow angle variations measured across the viscous blade wakes. This indicates that both the tip vortices and viscous wakes generated by these forward-swept blades would contribute significantly to the generation of interaction noise.

3) The time-averaged flow in the frame of reference of the front-rotor did not undergo any drastic changes as the rotor rotational speed was increased from the below flutter to the flutter operating condition.

4) The flow did not massively separate from the blades during flutter. Therefore, massive blade stall did not cause the flutter.

5) The flow about the blades was subsonic at both operating conditions. Consequently, shock waves did not cause the flutter.

6) The tips of the forward-swept front rotor blades were highly loaded at both operating conditions. This is thought to have been caused by the blade tips twisting under load to higher 
than expected effective blade angles. This high tip loading may have caused the blade flutter.

7) The high tip loading resulted in strong tip vortices and a very nonuniform flow downstream of the blade tips. The expected benefit of forward sweep as a means of making the wake flow downstream of the blades tips more uniform was not realized.

\section{REFERENCES}

1. Simonich, J., McCormick, D., and Haas, R.: The Role of Leading Edge Vortex Flows in Prop-Fan Interaction Noise. AIAA Paper 90-3977, October 1990.

2. Lavrich, P., Simonich, J., McCormick, D., and Parzych, D.: An Assessment of Wake Structure Behind Forward Swept and Aft Swept Propfans at High Loading. DGLR/AIAA Paper 92-02-154, May 1992.

3. Woodward, R.P., Hall, D.G., Podboy, G.G., and Jeracki, R.J.: Takeoff/ Approach Noise for a Model Counterrotation Propeller with a Forward-Swept Upstream Rotor. AIAA Paper 93-0596, January 1993. (NASA TM-105979) 


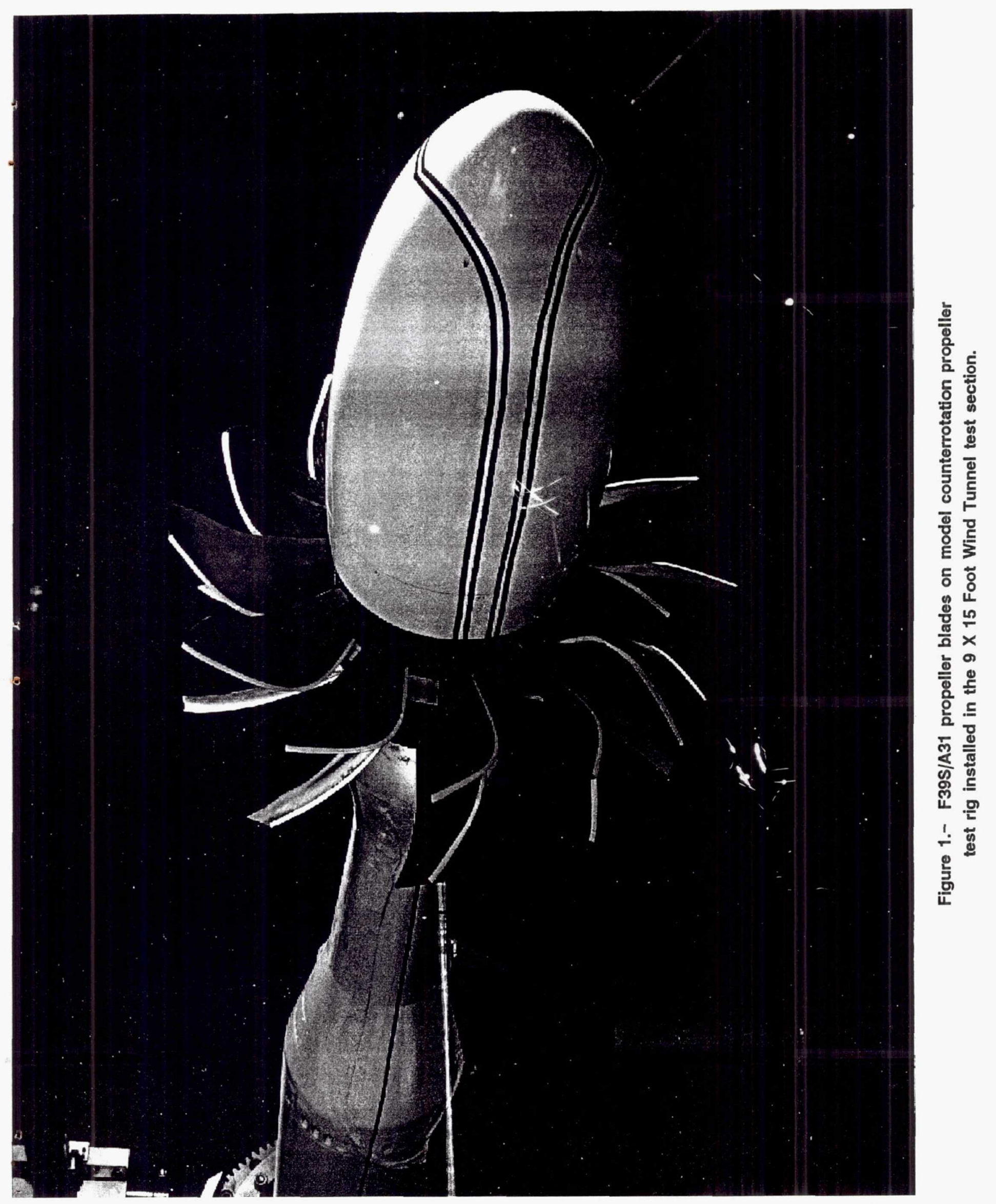


Page intentionally left blank 


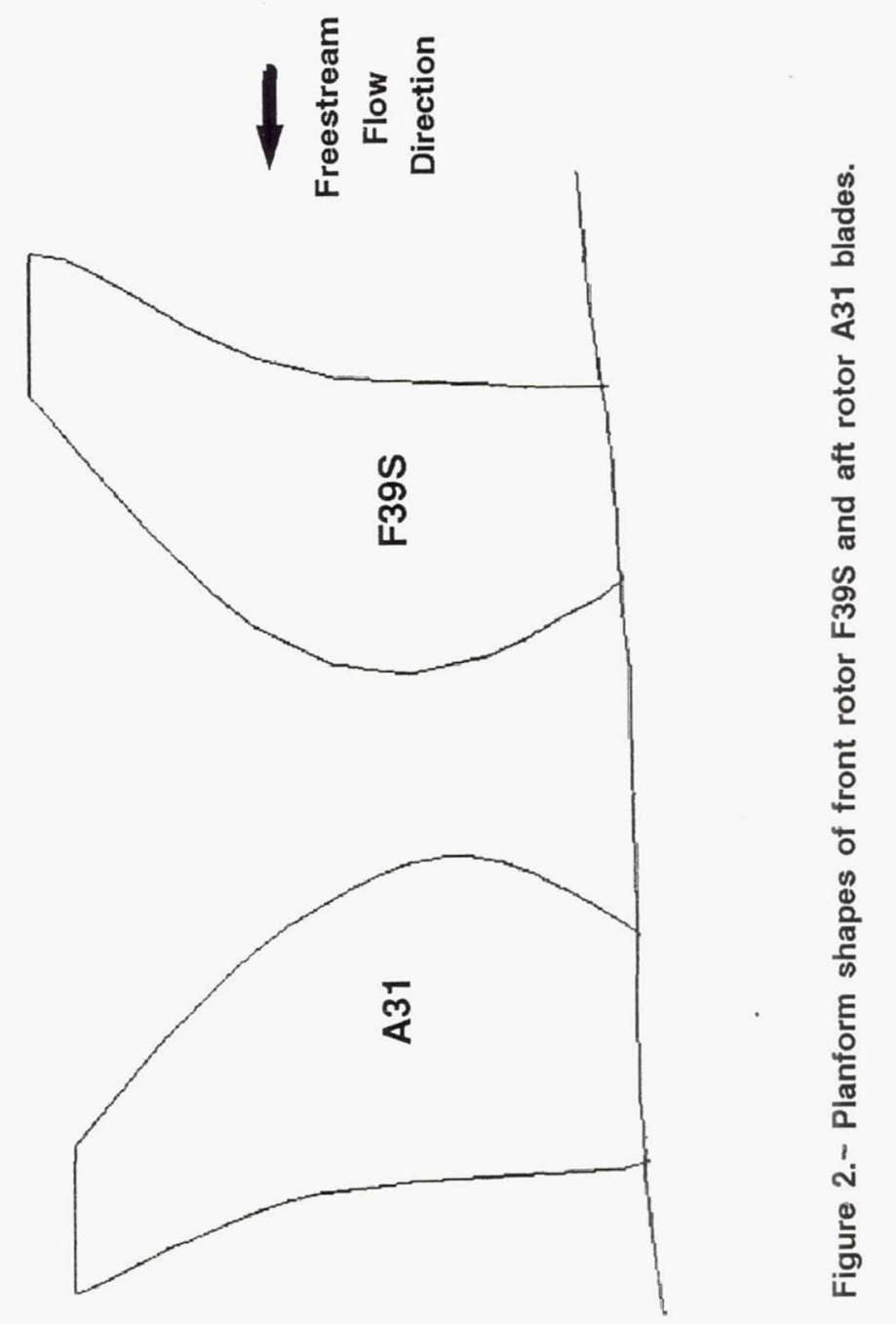


Page intentionally left blank 


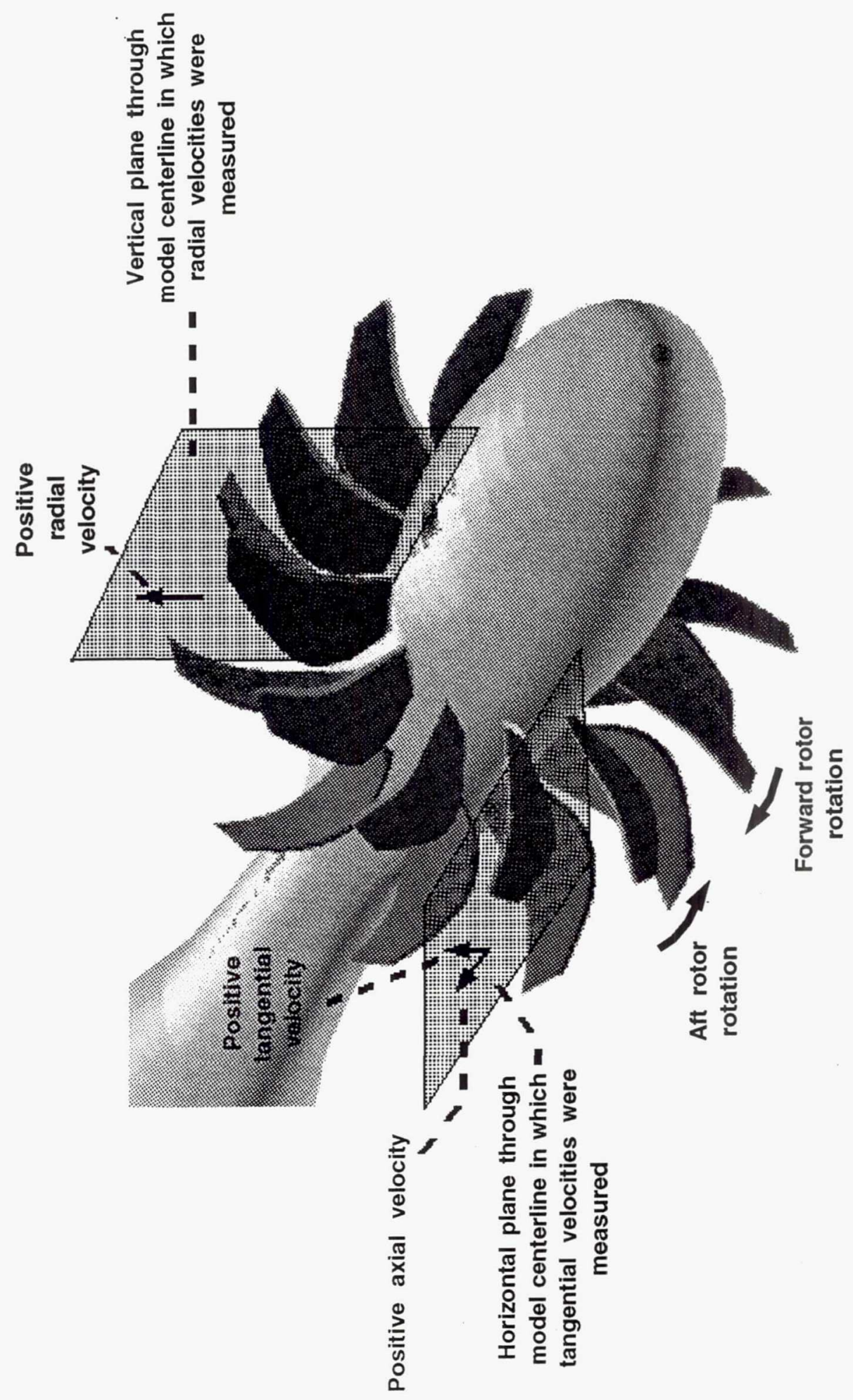

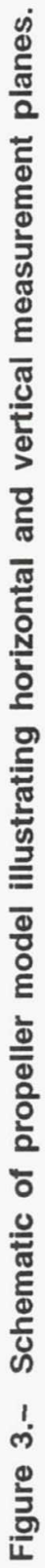


Page intentionally left blank 

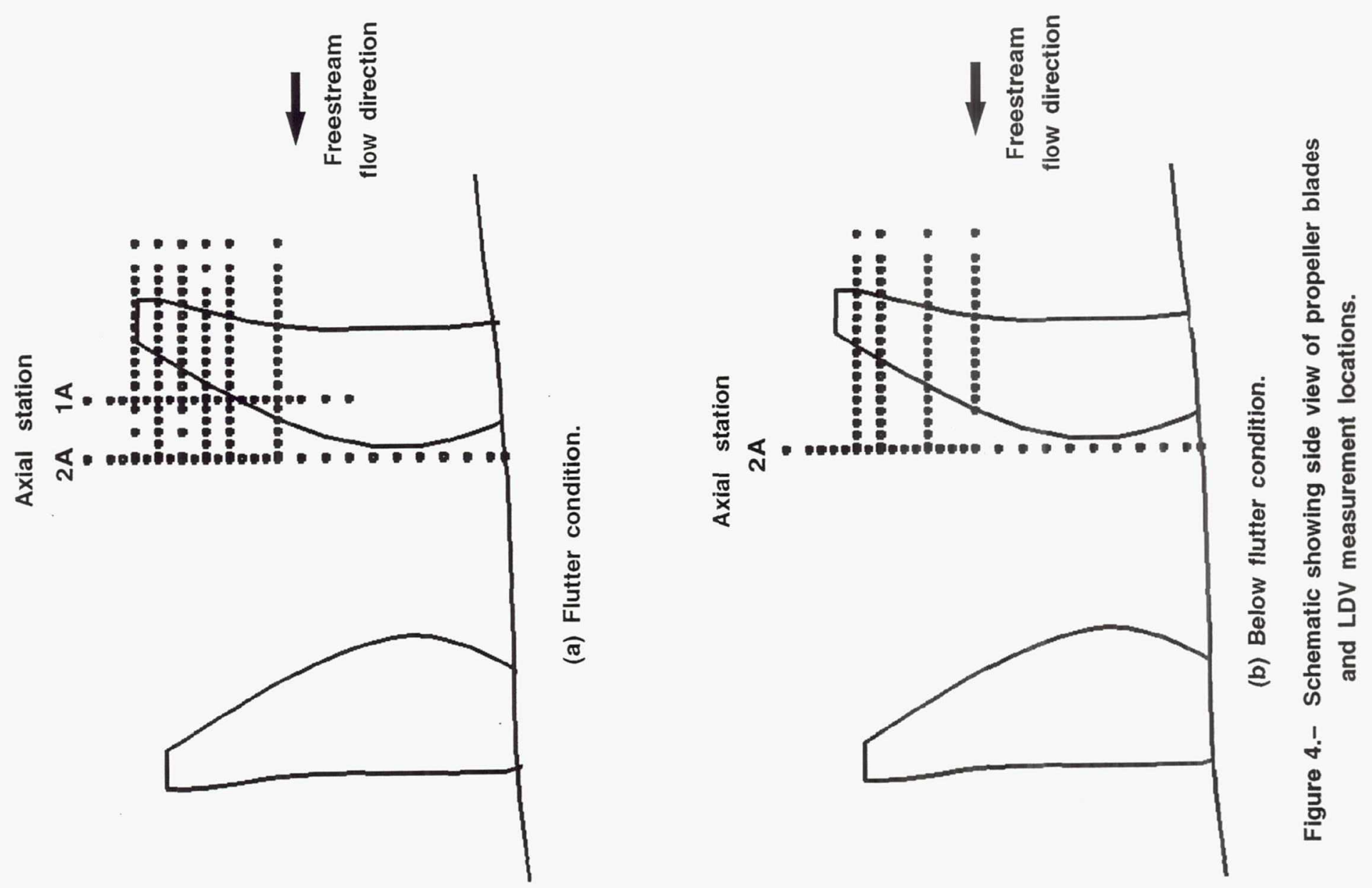
Page intentionally left blank 

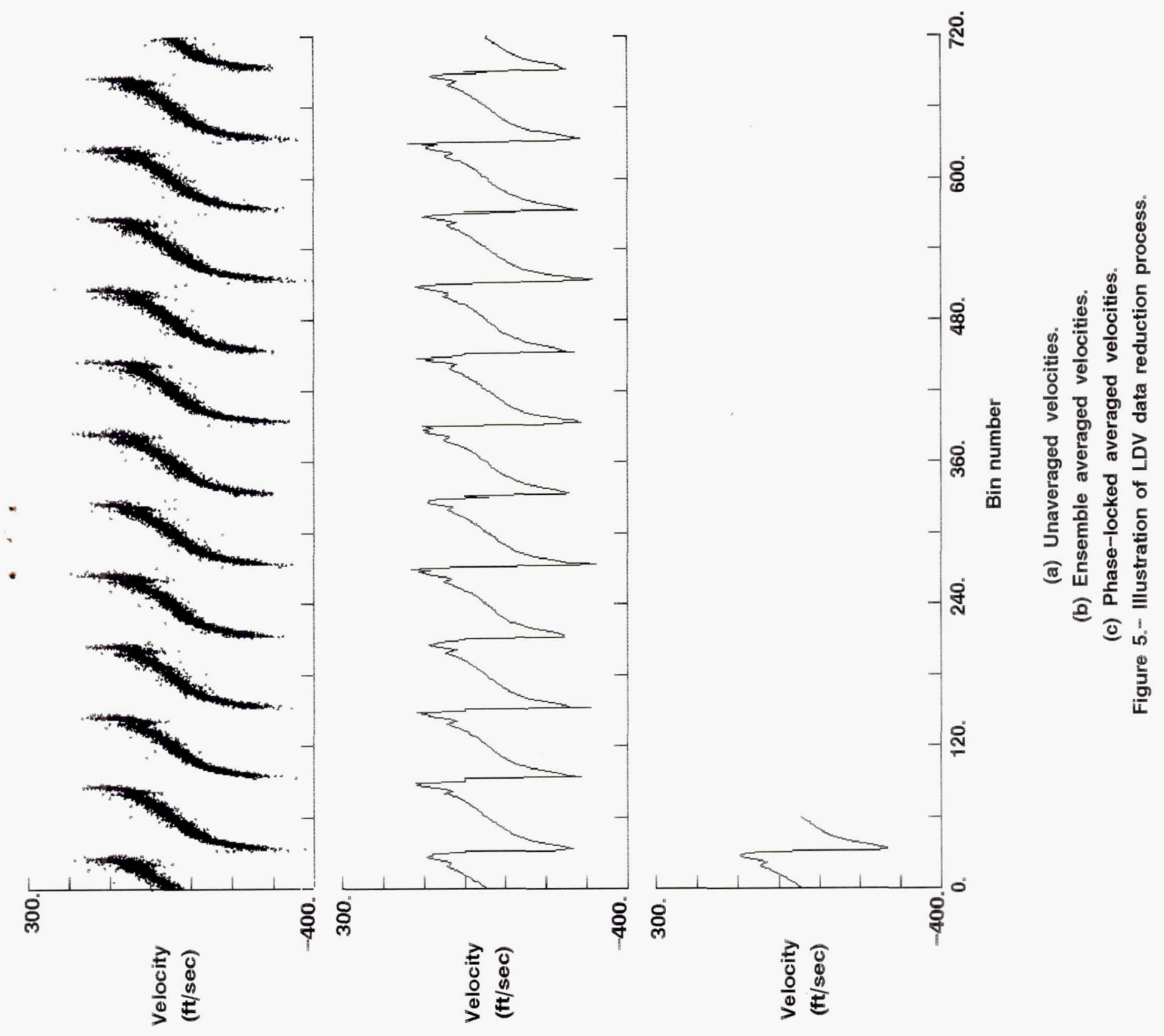
Page intentionally left blank 


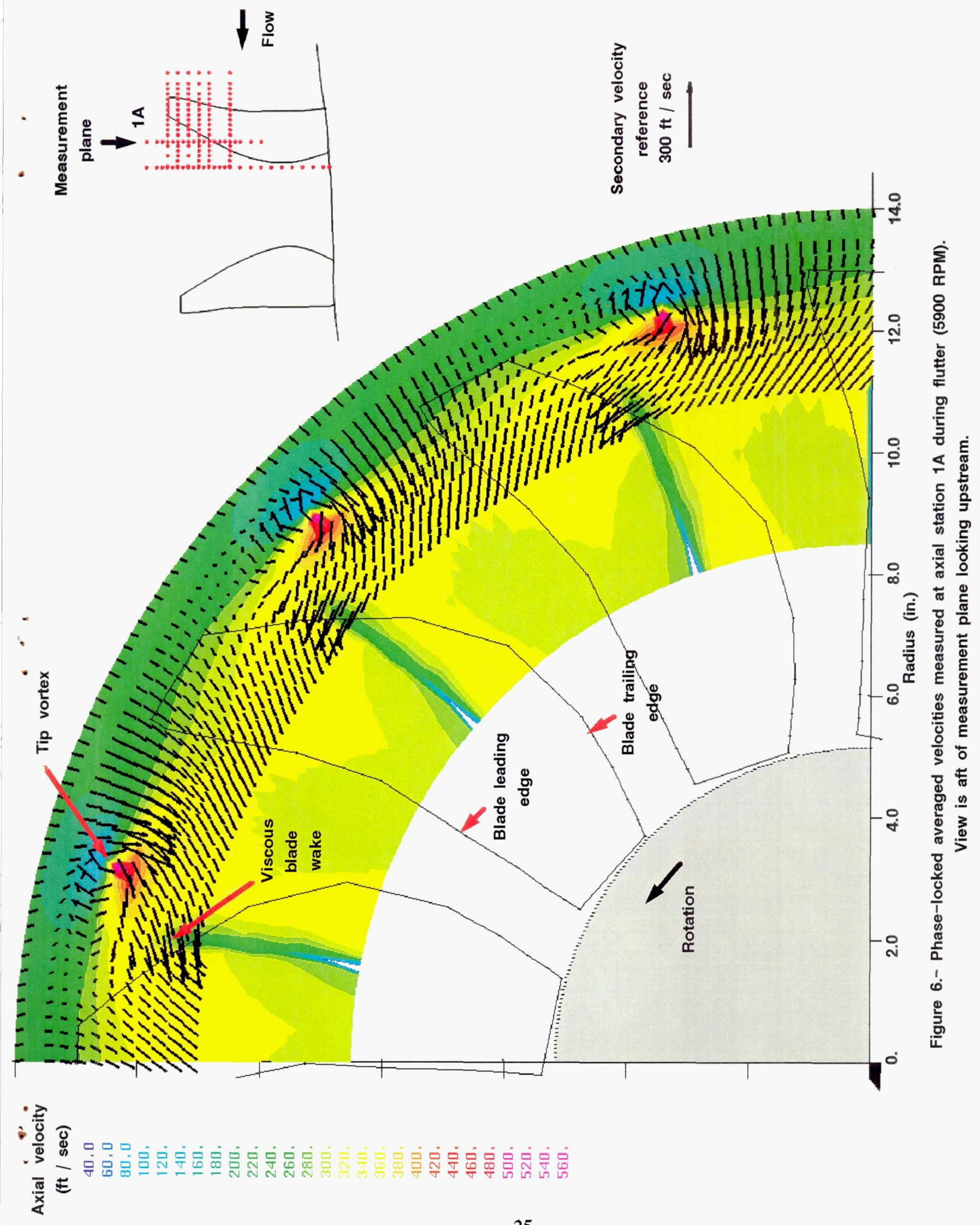


Page intentionally left blank 
Page intentionally left blank 


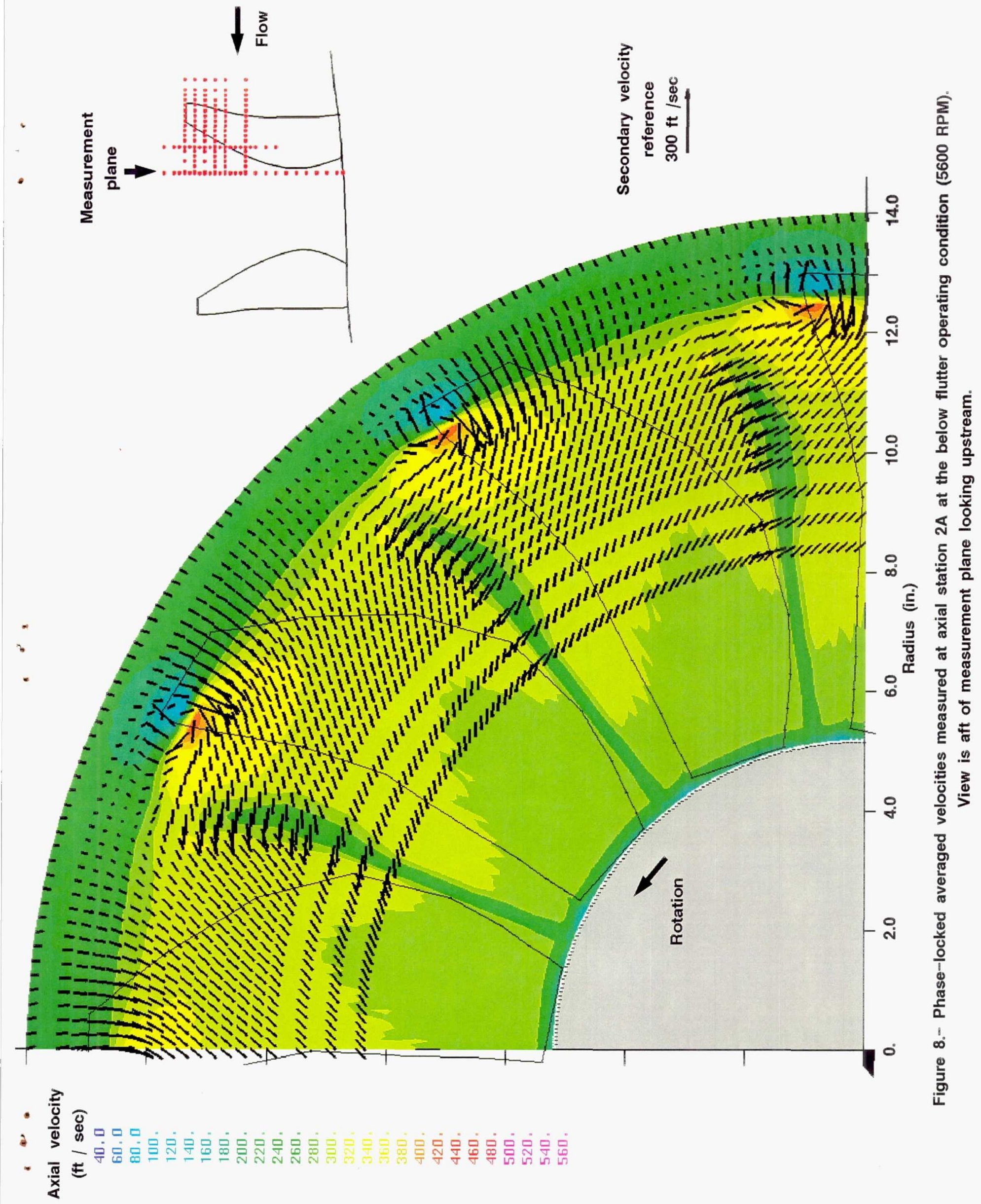


Page intentionally left blank 


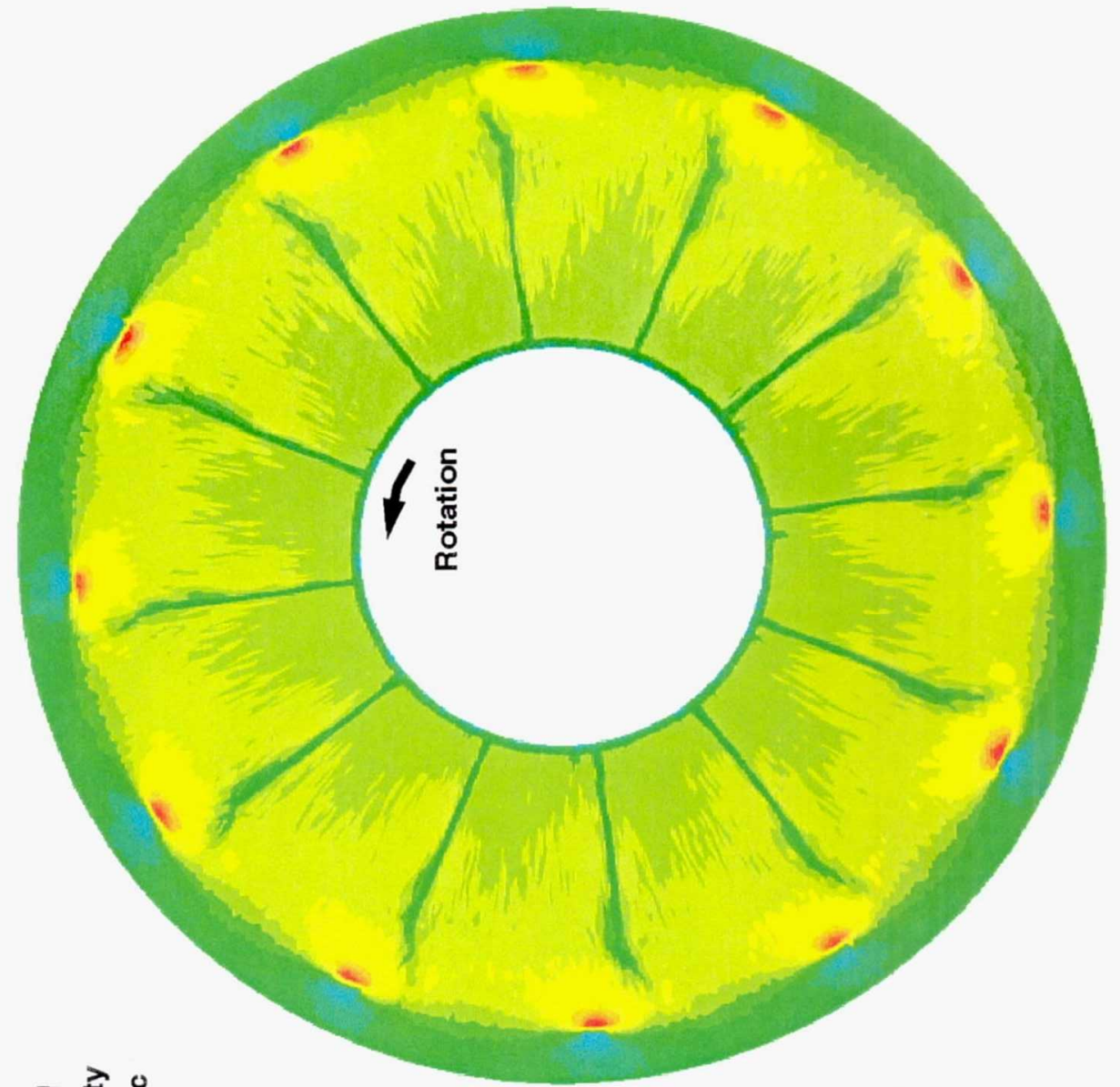

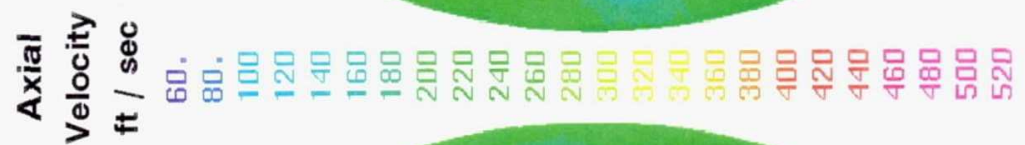

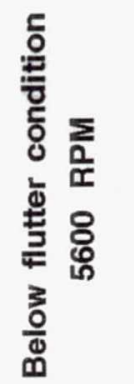

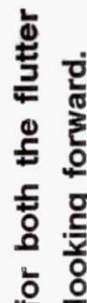

ส

离

छั

के

曲

造

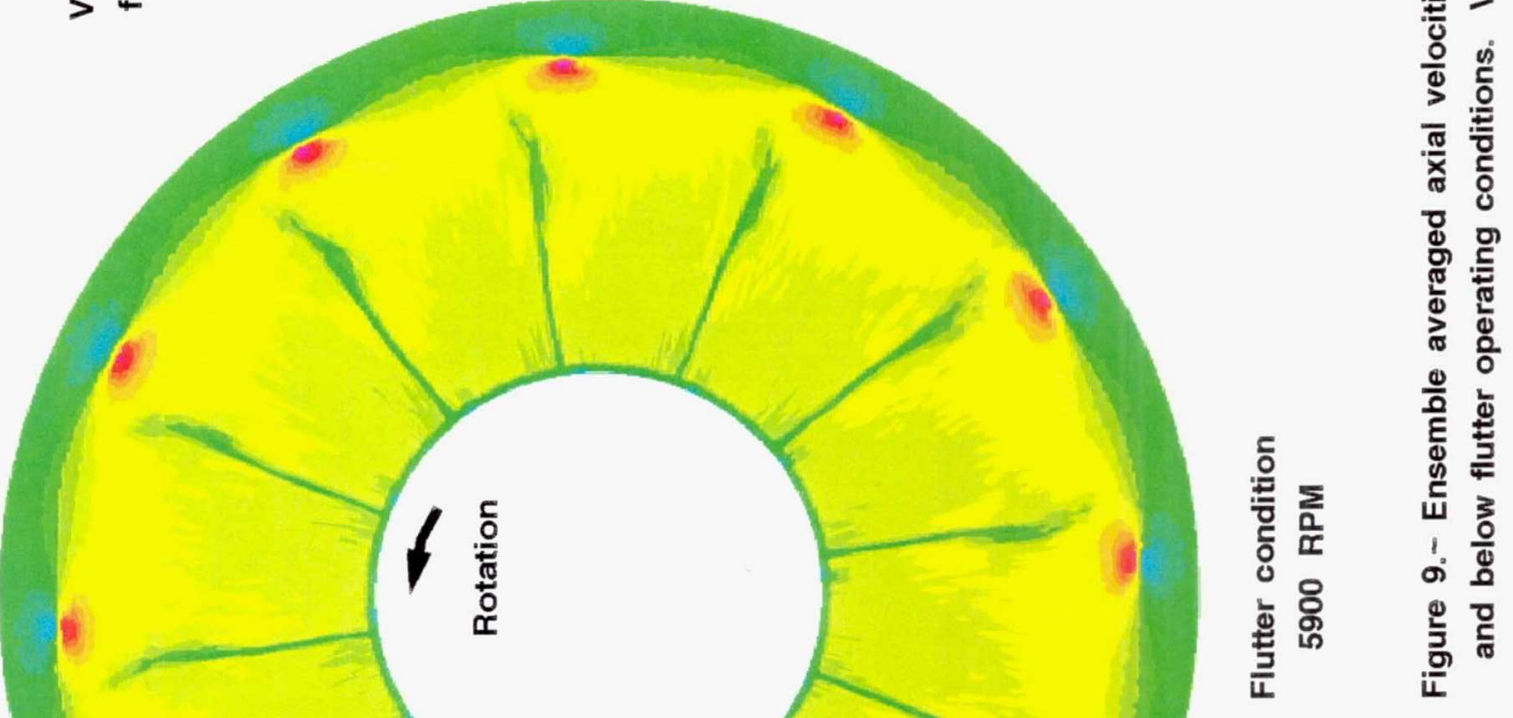


Page intentionally left blank 


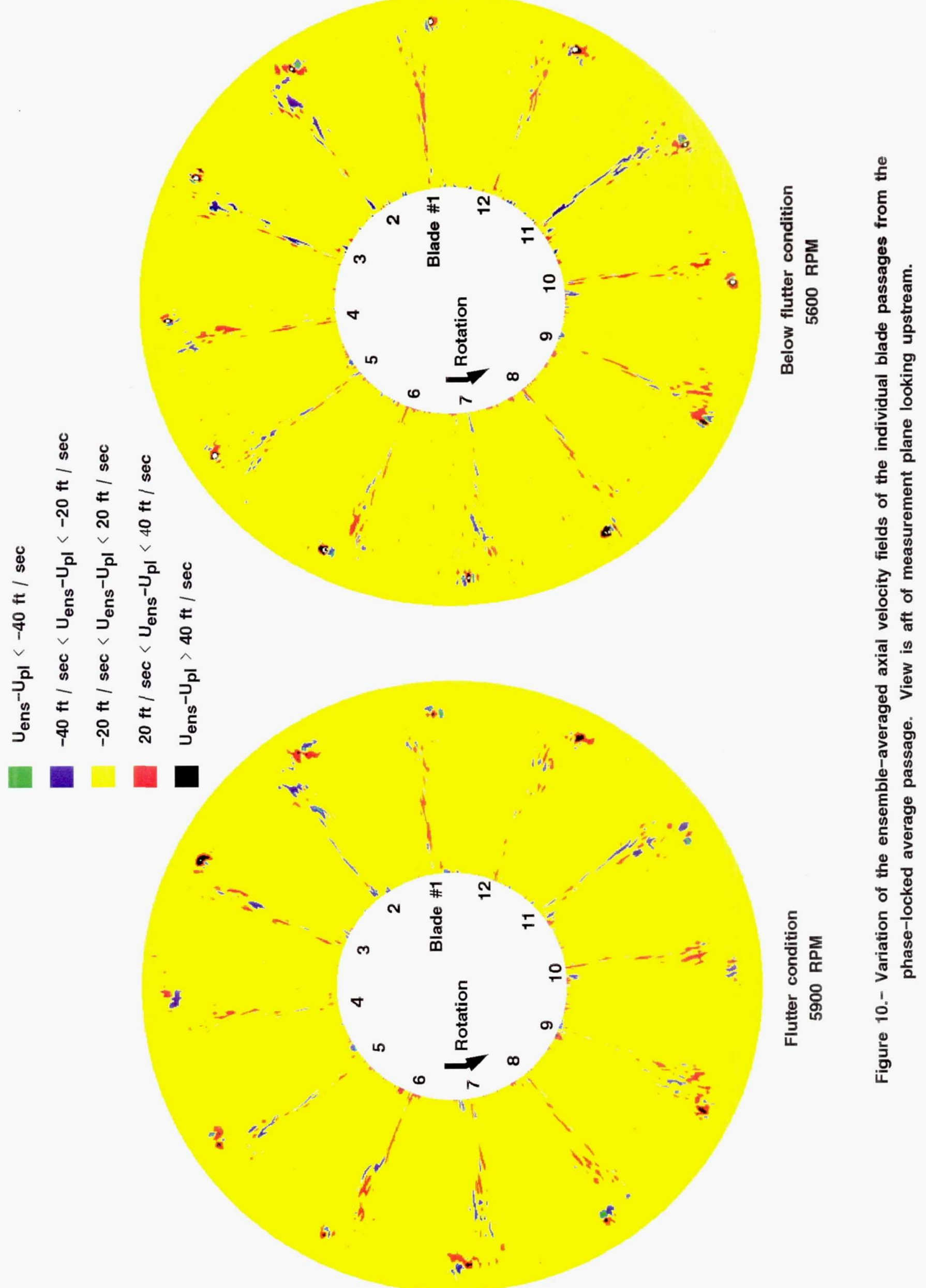


Page intentionally left blank 

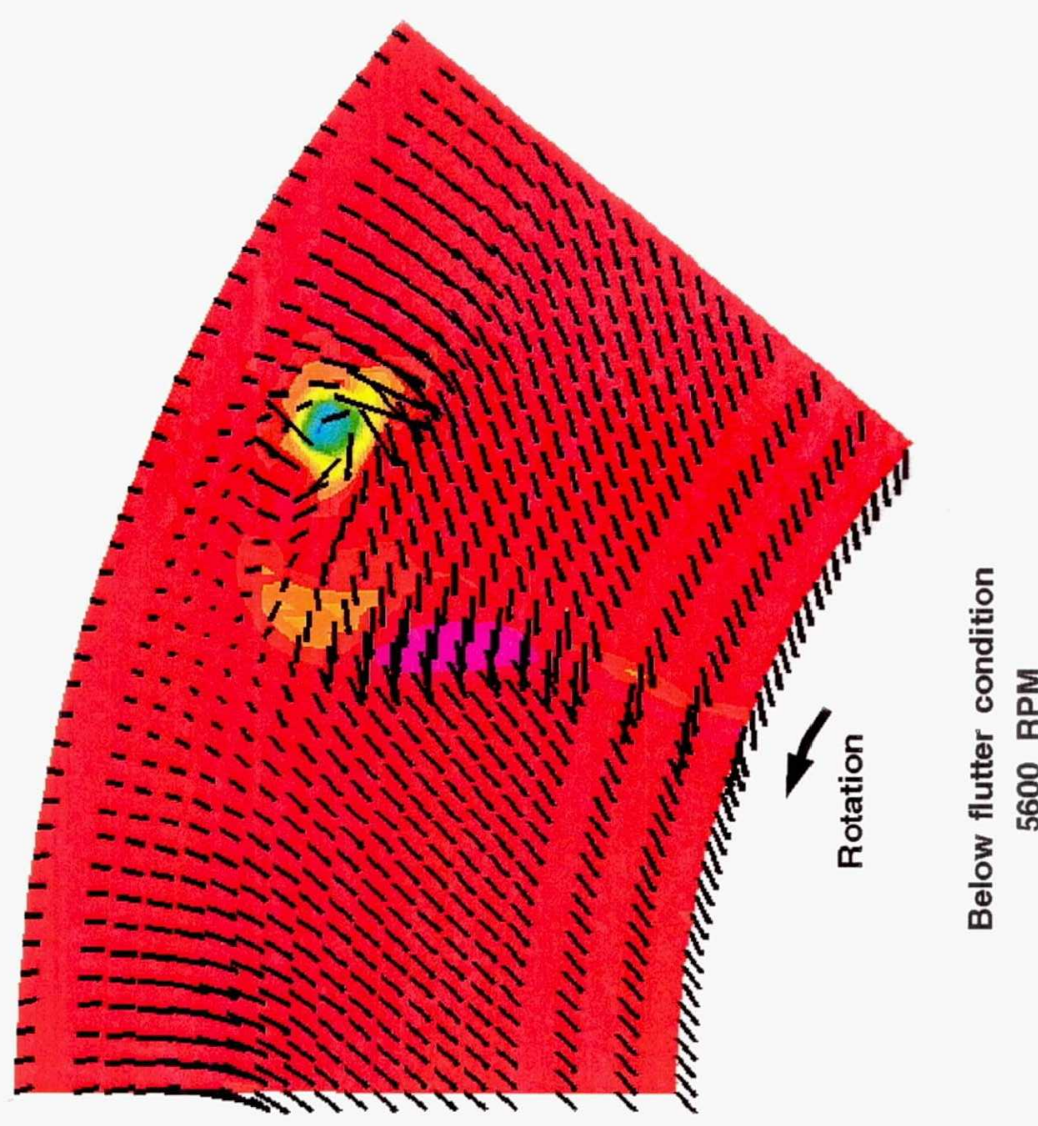

뫃

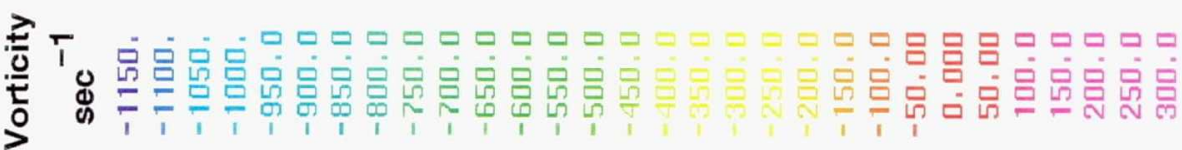

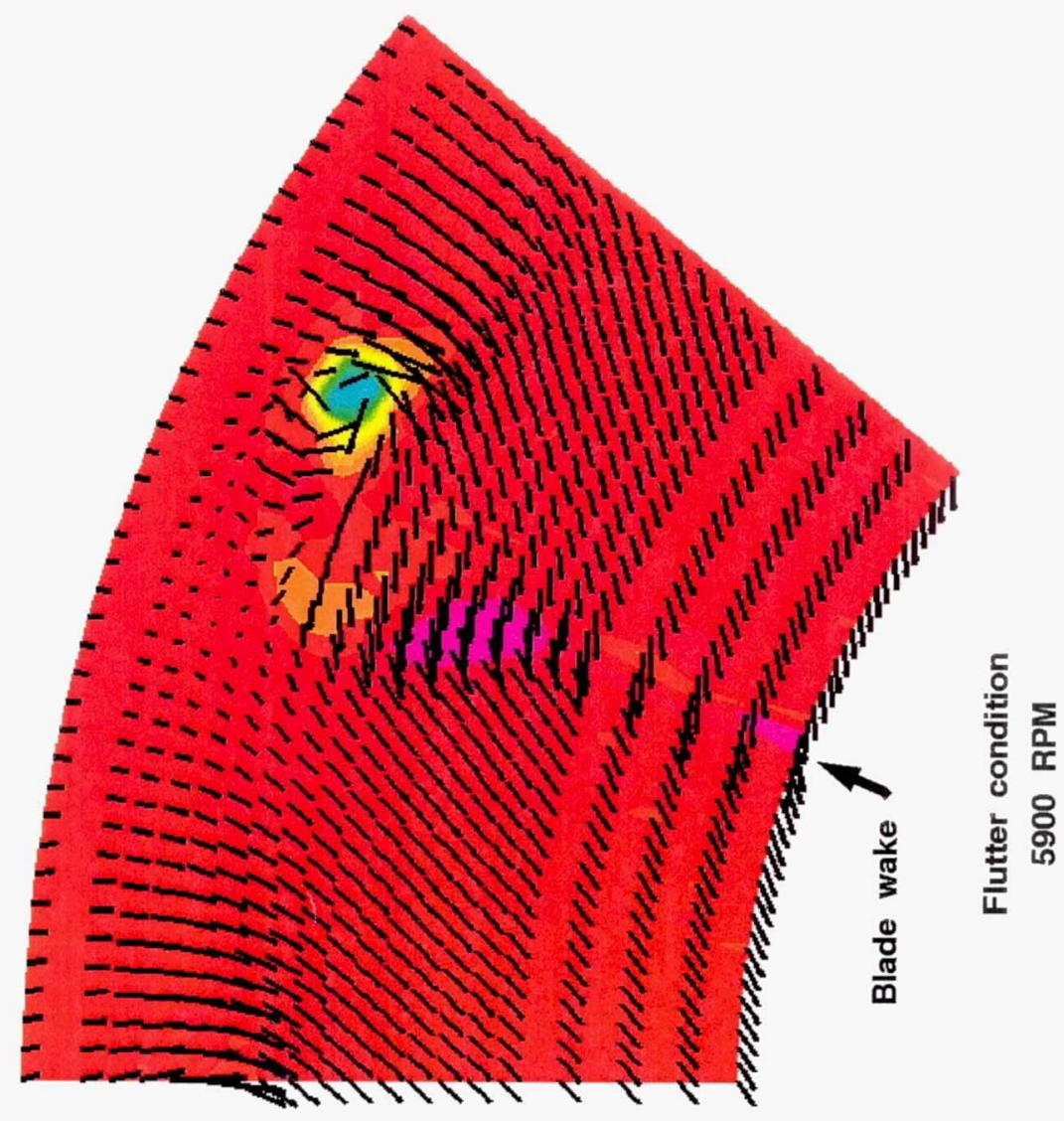


Page intentionally left blank 


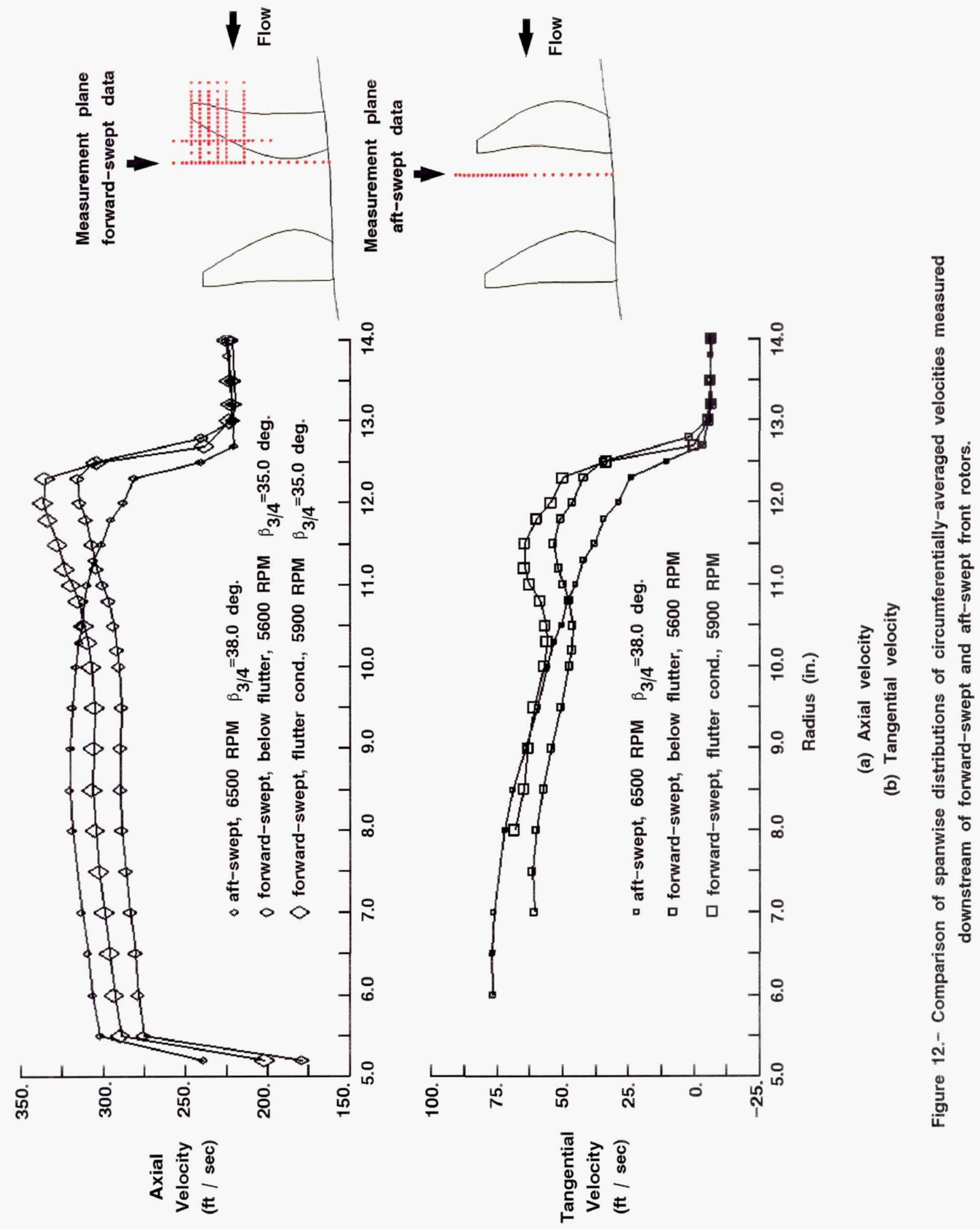


Page intentionally left blank 

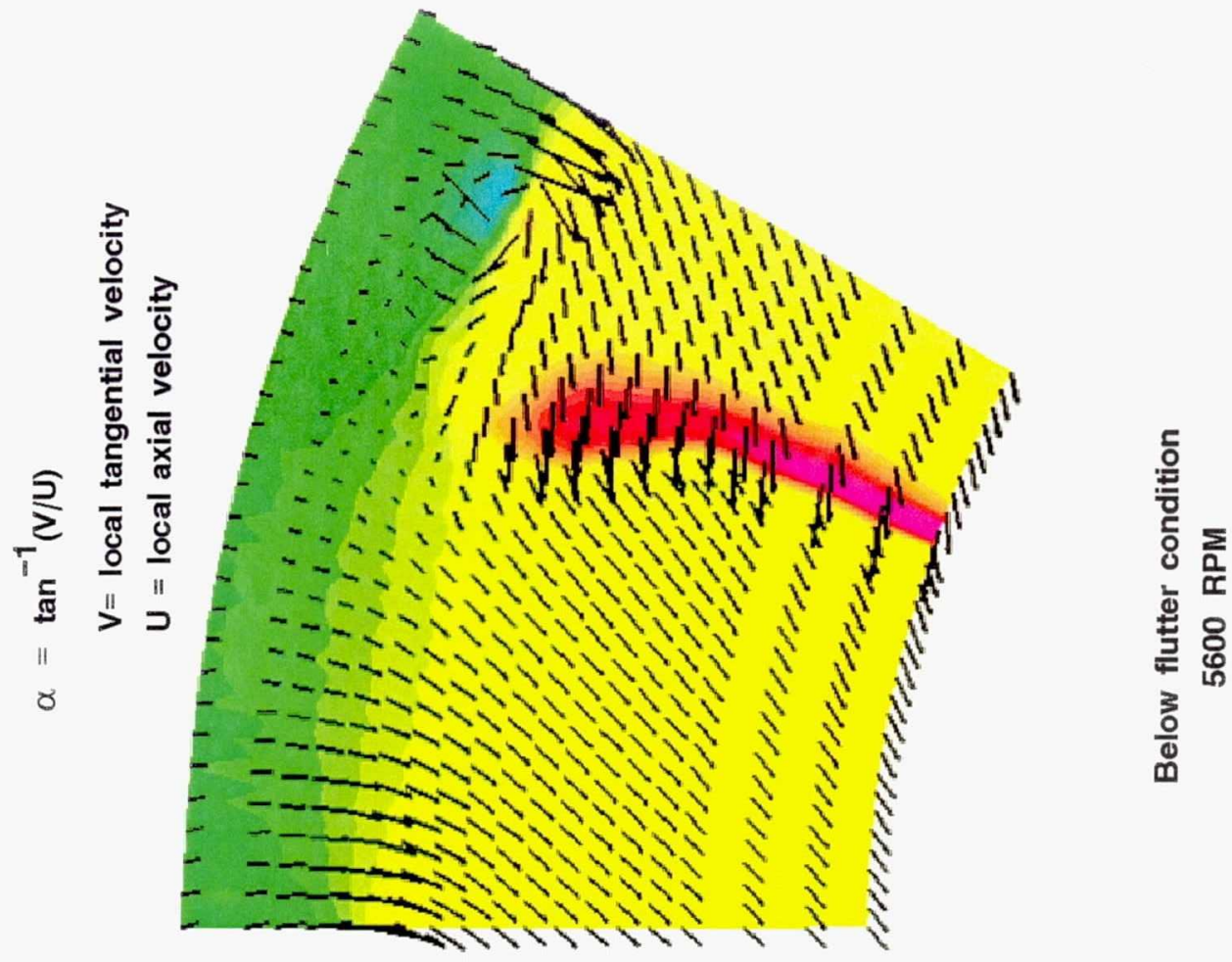

8
$\frac{0}{5}$
$\frac{5}{5}$
$\frac{3}{4}$

母ํ.

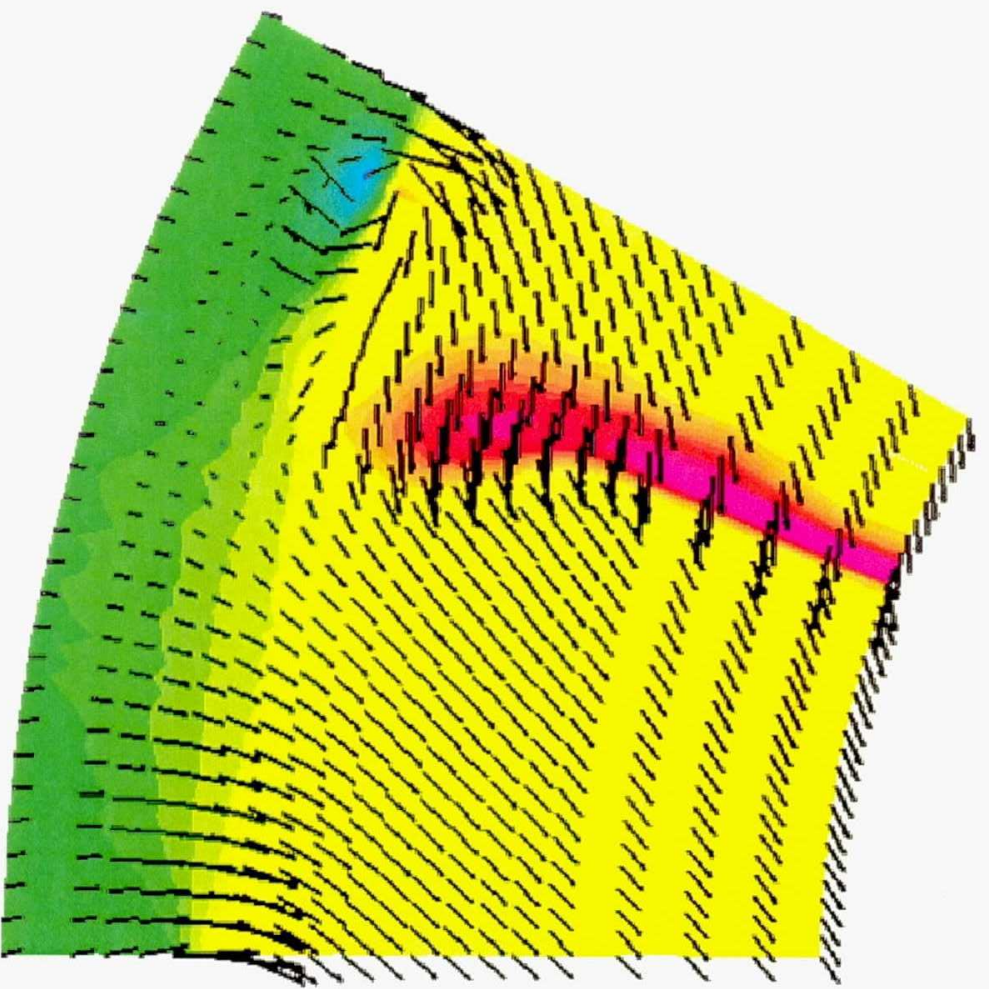

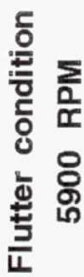

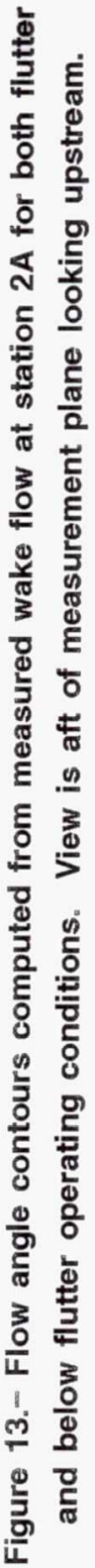


Page intentionally left blank 

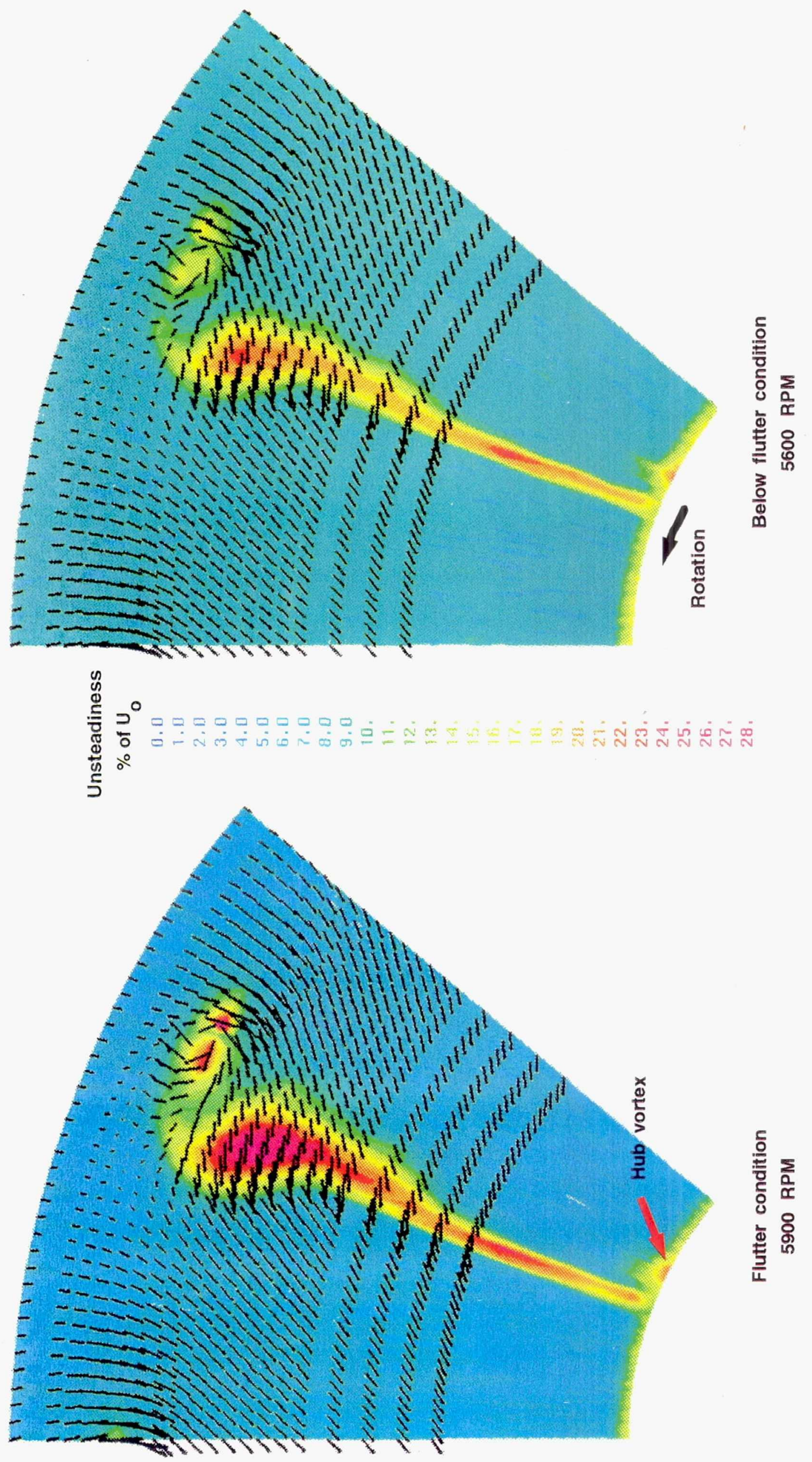

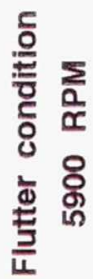

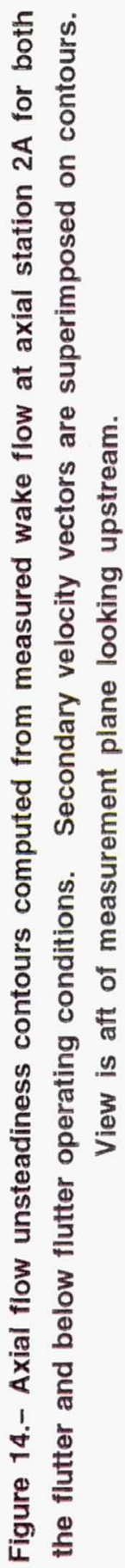


Page intentionally left blank 

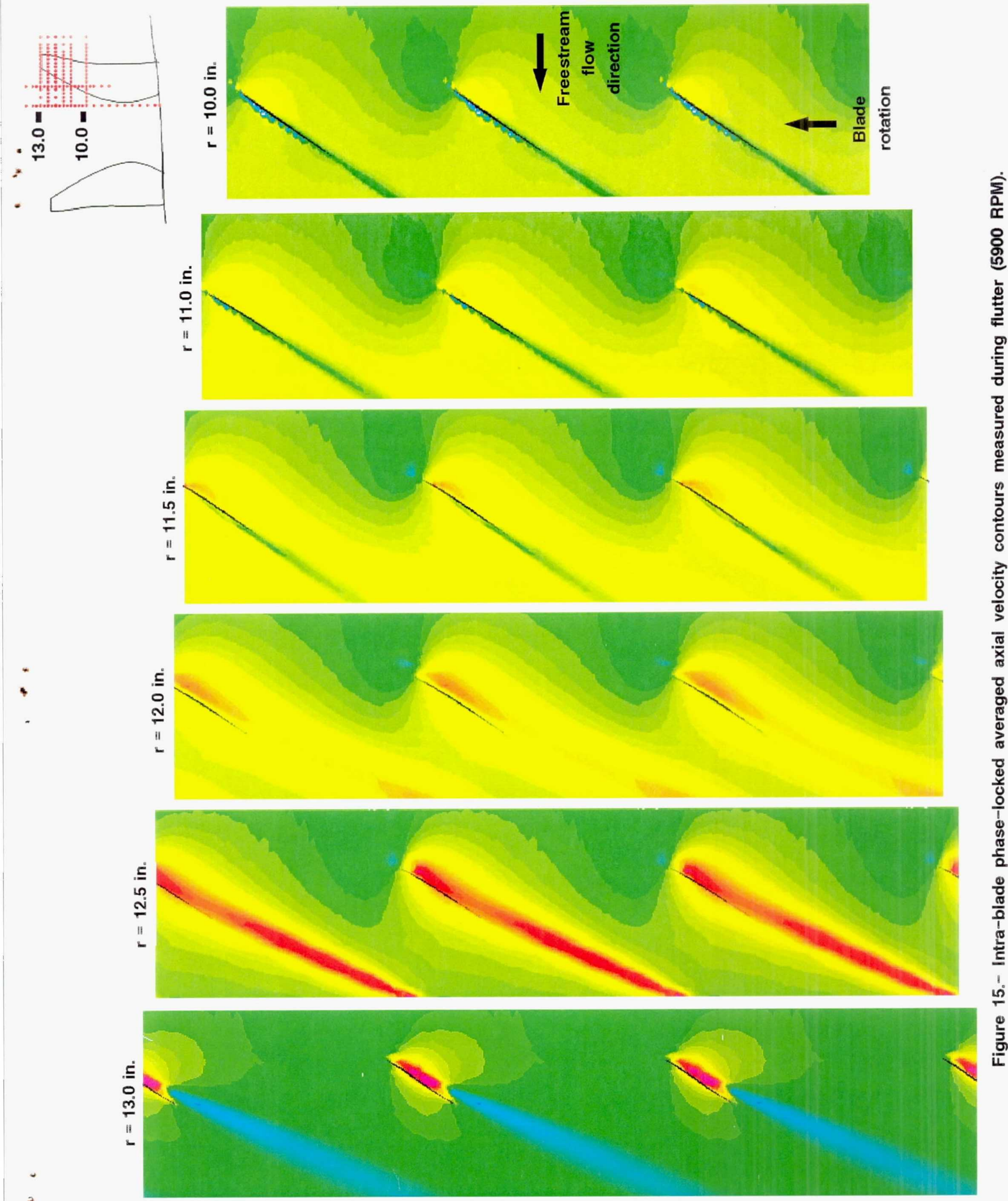

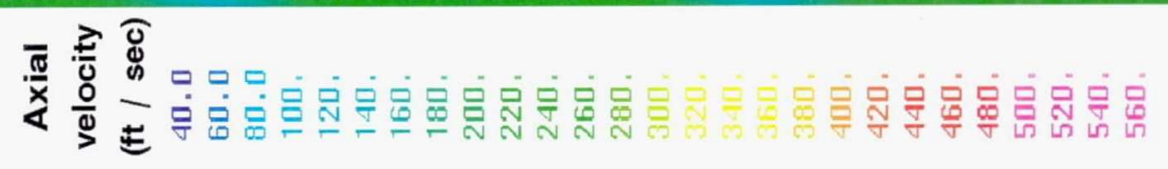


Page intentionally left blank 

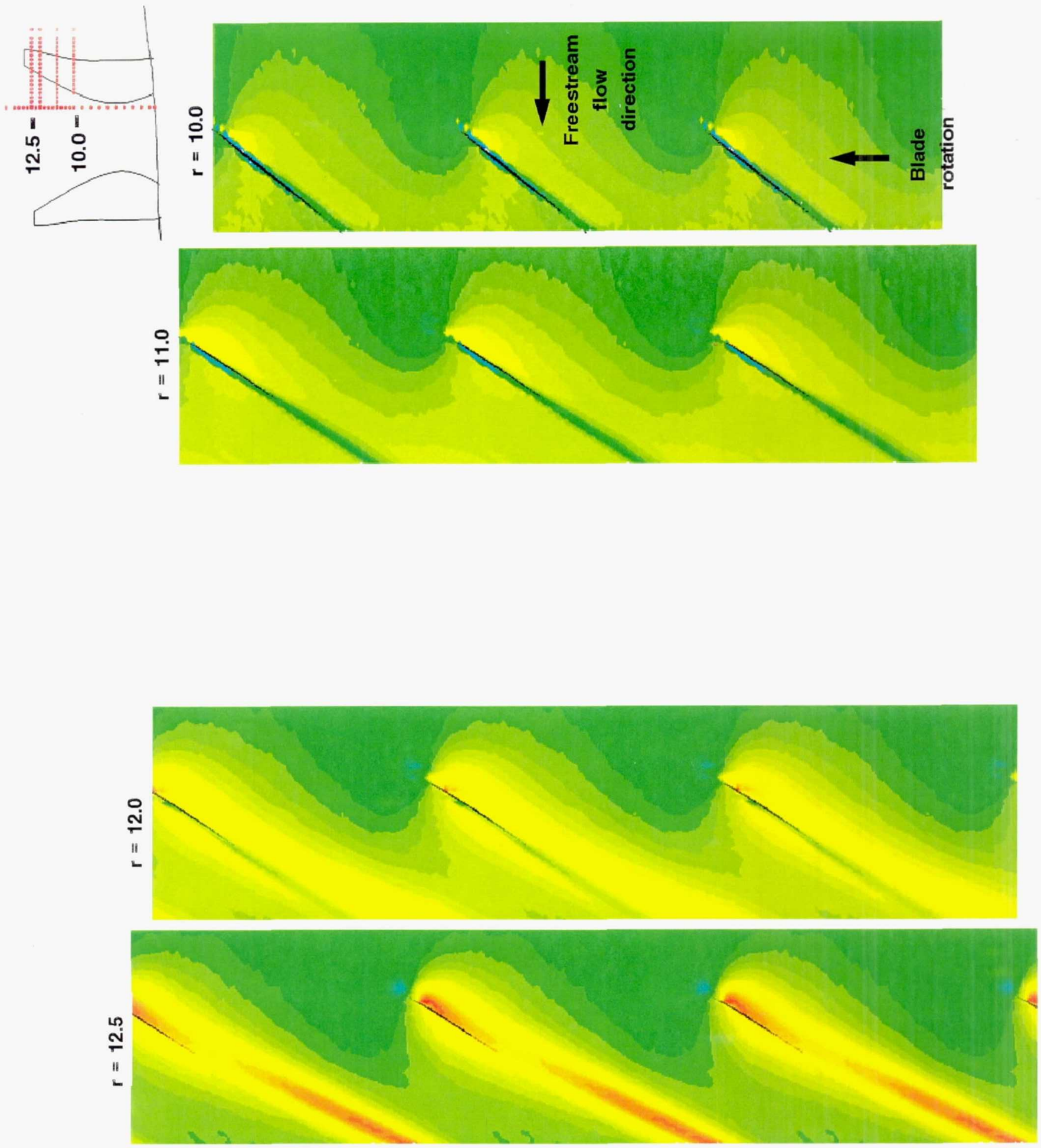
Page intentionally left blank 

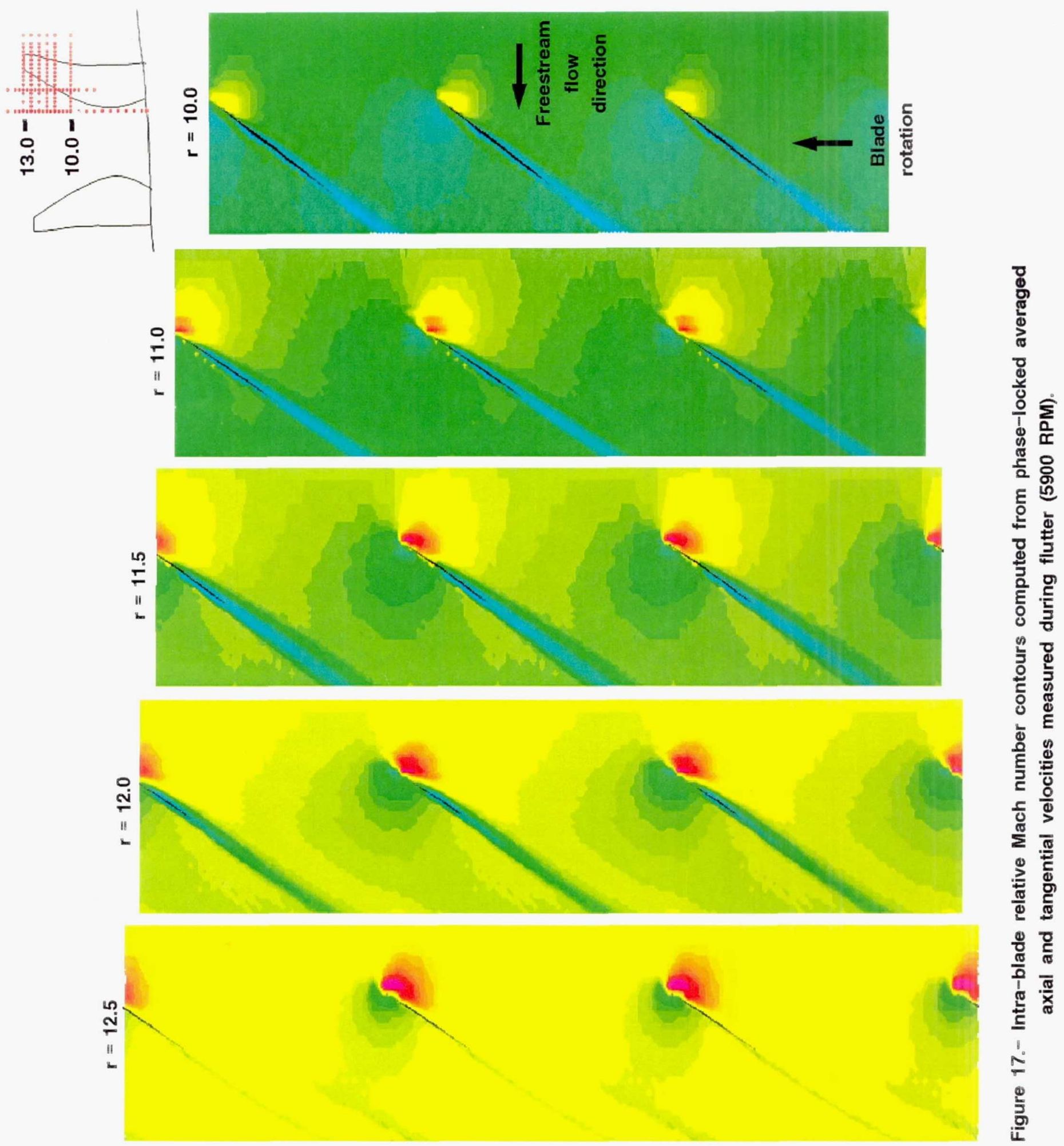

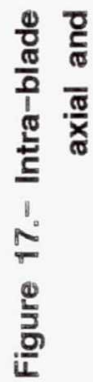

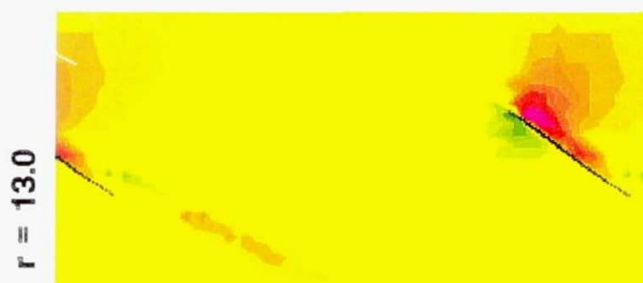

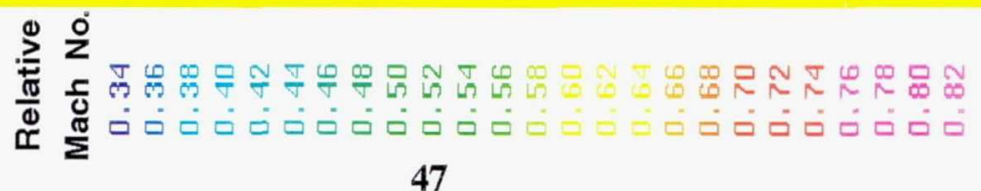


Page intentionally left blank 

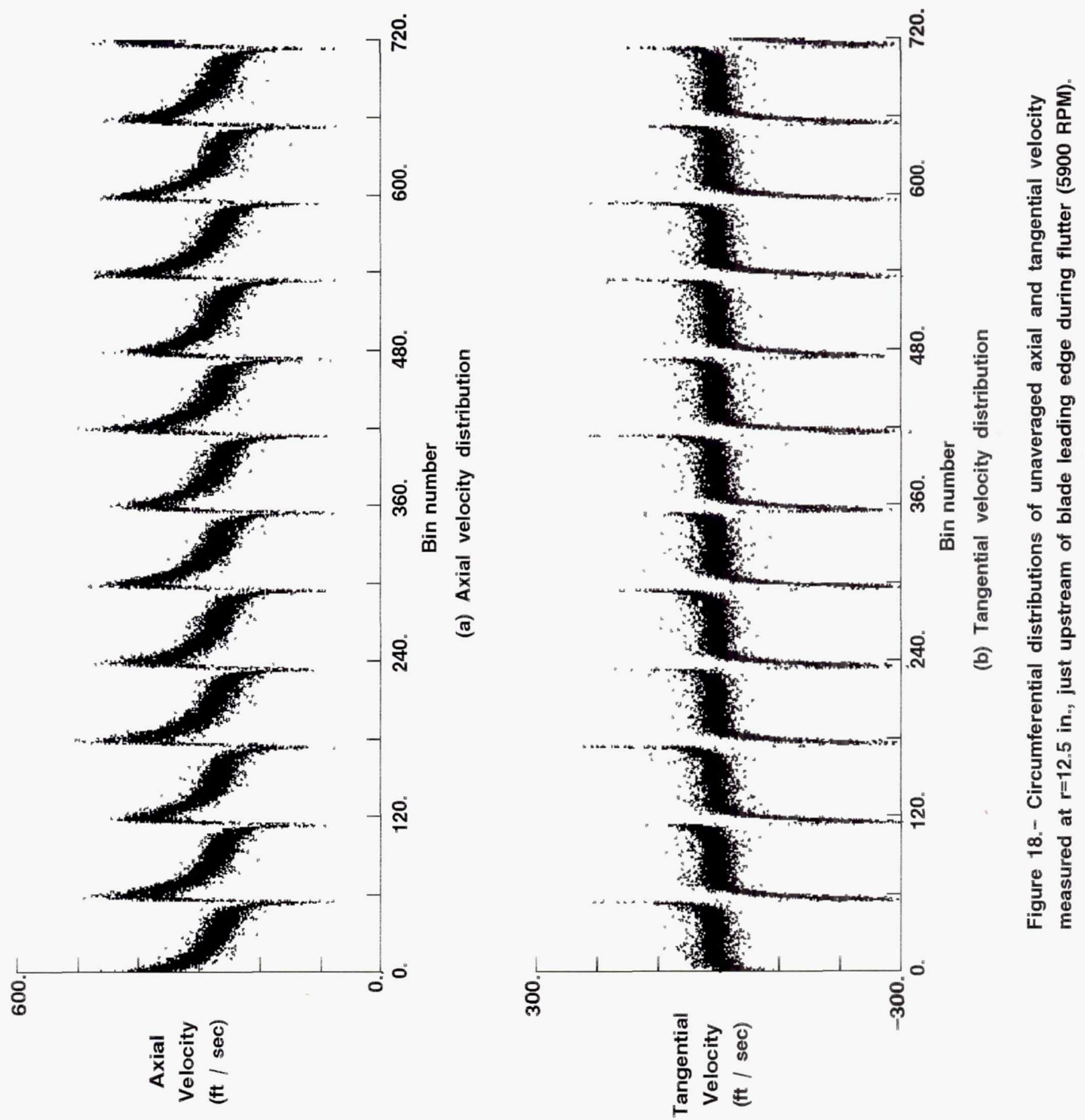
Public reporting burden for this collection of information is estimated to average 1 hour per response, including the time for reviewing instructions, searching existing data sources, gathering and maintaining the data needed, and completing and reviewing the collection of information. Send comments regarding this burden estimate or any other aspect of this collection of information, including suggestions for reducing this burden, to Washington Headquarters Services, Directorate for Information Operations and Reports, 1215 Jefferson Davis Highway, Suite 1204, Arlington, VA 22202-4302, and to the Office of Management and Budget, Paperwork Reduction Project (0704-0188), Washington, DC 20503.

\begin{tabular}{|l|l|l|}
\hline 1. AGENCY USE ONLY (Leave blank) & $\begin{array}{c}\text { 2. REPORT DATE } \\
\text { July } 1993\end{array}$ & $\begin{array}{r}\text { 3. REPORT TYPE AND DATES COVERED } \\
\text { Technical Memorandum }\end{array}$ \\
\hline
\end{tabular}

4. TITLE AND SUBTITLE

Laser Velocimeter Measurements of the Flow Field Generated by a Forward-Swept Propfan During Flutter

6. AUTHOR(S)

Gary G. Podboy and Martin J. Krupar
5. FUNDING NUMBERS

7. PERFORMING ORGANIZATION NAME(S) AND ADDRESS(ES)

National Aeronautics and Space Administration

Lewis Research Center

Cleveland, Ohio 44135-3191

WU-535-03-10

9. SPONSORING/MONITORING AGENCY NAME(S) AND ADDRESS(ES)

National Aeronautics and Space Administration

Washington, D.C. 20546-0001

8. PERFORMING ORGANIZATION

REPORT NUMBER

E-7903

10. SPONSORING/MONITORING AGENCY REPORT NUMBER

NASA TM-106195

AIAA-93-2919

\section{SUPPLEMENTARY NOTES}

Prepared for the 24th AIAA Fluid Dynamics Conference, Orlando, Florida, July 6-9, 1993. Responsible person, Gary G. Podboy, (216) 433-3916.

12a. DISTRIBUTION/AVAILABILITY STATEMENT

12b. DISTRIBUTION CODE

Unclassified - Unlimited

Subject Category 02

\section{ABSTRACT (Maximum 200 words)}

Results are presented from an investigation to measure the flow field generated by a forward-swept propfan operating in flutter at a low forward velocity. For comparison to the flutter condition, flow field data are also presented for a slightly reduced rotational speed just below flutter. The forward-swept propfan was tested as the front rotor of a counterrotating pusher propeller. A laser Doppler velocimeter (LDV) was used to measure the velocity field in planes normal to the model centerline downstream of the rotor and in planes of constant radius within the blade passages at each operating condition. A comparison of the data taken at the two different operating conditions indicated that the mean, time-averaged flow about the blades did not change drastically as the propfan rotational speed was increased from the stable operating point to the flutter condition. No regions of flow separation could be identified in the data plots of the mean intrablade flow field. The data also indicate that the relative flow about the blades remained subsonic during flutter operation. The blades were found to have a higher than expected tip loading at both operating conditions. This is thought to have been caused by the outer blade sections twisting under load to higher than expected effective blade angles. This high tip loading resulted in strong vortices and a very nonuniform flow downstream of the tips of the forward-swept blades. This high tip loading may also have caused the blade flutter.

\section{SUBJECT TERMS}

Propfan; Flutter; Laser Doppler velocimeter

17. SECURITY CLASSIFICATION OF REPORT Unclassified
18. SECURITY CLASSIFICATION OF THIS PAGE Unclassified
19. SECURITY CLASSIFICATION OF ABSTRACT Unclassified 